\title{
Operational planning of combined heat and power plants through genetic algorithms for mixed 0-1 nonlinear programming
}

\author{
Hariharan Gopalakrishnan, Dragoljub Kosanovic \\ Department of Mechanical and Industrial Engineering, University of Massachusetts
}

160 Governors Drive, Amherst, MA 01003, USA

\begin{abstract}
This paper is concerned with short-term (up to 24 hours) operational planning in combined heat and power plants for district energy applications. In such applications, heat and power demands fluctuate on an hourly basis due to changing weather conditions, time-of-day factors and consumer requirements. Plant energy efficiency is highly dependent on ambient temperature and operating load since equipment efficiencies are nonlinear functions of these parameters. In operational planning strategies, nonlinear equipment characteristics are seldom taken in to account, resulting in plants being operated at sub-par efficiencies. In order to operate plants at highest possible efficiencies, scheduling strategies which take in to account nonlinear equipment characteristics need to be developed. For such strategies, a mixed 0-1 nonlinear programming formulation is proposed. The problem is nonconvex and hence global optimality conditions are unknown. Classical techniques like branch-and-bound may not produce integer feasible solutions, may cut off the global optima and have an exponential increase in CPU time for a linear increase in planning horizon size. As an alternative, a solution method through genetic algorithms is proposed in which genetic search is applied only on 0-1 variables and gradient search is applied on continuous variables. The proposed method is a nonlinear extension of the one originally developed by Sakawa et al [Sakawa M, Kato K, Ushiro S. Operational planning of district heating and cooling plants through genetic algorithms for mixed 0-1 linear programming. European Journal of Operational Research 2002;137(3):677-687]. Numerical experiments show the proposed genetic algorithm method is more consistent in finding integer feasible solutions, finds solutions with lower optimality gaps and has reasonable CPU time as compared to branch-and-bound. From an application perspective, the proposed scheduling strategy results in 5-11\% increase in plant energy efficiency.
\end{abstract}

\section{Keywords}

CHP, Energy efficiency, Thermodynamics, Scheduling, MINLP, Genetic algorithms

\section{Nomenclature \\ GT: Gas turbine \\ DB: Duct burner}

HRSG: Heat recovery steam generator

B1: High pressure steam boiler

B2: Low pressure steam boiler

B3: Low pressure steam boiler

ST1: High pressure steam turbine

ST2: Low pressure steam turbine

DS1: High pressure desuperheater

DS2: Low pressure desuperheater

S1: High pressure district steam supply

S2: Low pressure district steam supply

I: Index set of equipment [GT,DB,B1,B2,B3,ST1,DS1,ST2,DS2]

A: Ambient temperature $(\mathrm{K})$

(C) 2015. This manuscript version is made available under the Elsevier user license http://www.elsevier.com/open-access/userlicense/1.0/ 
E: Electric power $(\mathrm{kW})$

F: Fuel power (kW)

Q: Steam power $(\mathrm{kW})$

$\eta$ : Combustion efficiency (dimensionless)

$\varepsilon:$ Heat transfer efficiency (dimensionless)

$\phi:$ Start/stop energy (kWh/switch)

$\delta$ : On-off status ( 0 or 1$)$

t: Given hour

T: Planning horizon size (hours)

$\mathrm{P}(\mathrm{t})$ : Hourly problem

$\mathrm{P}(\mathrm{t}, \mathrm{T})$ : Multi-period problem

$\mathrm{CV}$ : Continuous variable

$\mathrm{BV}$ : Binary variable

Z: Objective function

LB: Lower bound on objective function value

NLIC: Nonlinear inequality constraint

NLEC: Nonlinear equality constraint

LIC: Linear inequality constraint

VB: Variable bound

PR: Present schedule

BB: Branch-and-bound schedule

GA: Genetic algorithm schedule

\section{Introduction}

Combined heat and power (CHP) plants are designed to utilize residual heat from electric power generation cycles, thereby boosting energy efficiency to levels much higher than those achieved by power-only plants. CHP plants are widely used in chemical, paper/pulp and petroleum industries since these applications have simultaneous need for process heat and electric power. District energy is another application where CHP plants are widely used. Residential and commercial districts require heat for space conditioning and hot water and electricity for lighting and appliances. CHP plants cater to both needs simultaneously in an energy efficient way.

In district energy applications, heat and power demands fluctuate on an hourly basis due to changing weather conditions, time-of-day factors and consumer requirements, making it important to keep adjusting equipment loads within the plant. Operational planning (or scheduling) involves skillful determination of equipment loads such that certain objective functions are optimized subject to energy demand satisfaction and safe equipment load constraints. Most times objective functions are related to financial profits based on purchase prices of different fuels and selling prices of heat and power. Such cost optimization problems are modeled as mixed integer linear programming (MILP) problems and the resulting optimum solutions help in running plants profitably. But from a thermodynamic perspective, plant efficiency is highly dependent on ambient temperature and operating load since equipment efficiencies are nonlinear functions of these parameters. In operational planning strategies, nonlinear equipment characteristics are seldom taken in to account, resulting in plants being operated at sub-par efficiencies. It is highly likely that even though plants are operated cost optimally (reason being the relative differences in cost coefficients of the objective function), from a thermodynamic perspective the plants are operated inefficiently (it is possible to inefficiently use large quantities of cheaper fuels and yet be financially profiting). Hence, from a theoretical perspective it becomes interesting to investigate possibilities of operating plants solely on the basis of optimizing energy efficiency. In order to operate plants at highest possible efficiencies, scheduling strategies which take in to account nonlinear equipment characteristics must be developed. For such scheduling problems, this paper proposes a mixed integer nonlinear programming (MINLP) methodology. 
The MINLP framework is one of the richest modeling paradigms applicable to scheduling problems in many different types of energy plants. But computational solution techniques are difficult to implement and there is no guarantee of finding global optimal solutions. For ease of implementation, integer aspects can be relaxed and linear approximations can be made. These will help in producing quick solutions, but they might not reflect physical realities. For example, the permissible operating range for medium to large-sized steam boilers is either $0 \%$ load (off status) or between 20 and 100\% load. While formulating an operational planning problem, if the load (decision variable) is assumed to be continuous between the lower and upper bounds of 0 and 100\%, then it could lead to solutions in which the optimum load is between 0 and $20 \%$, which might not be acceptable to the decision maker/plant operator (in automated plants the feedback control systems will reject such I/O signals). On the other hand, if the lower bound is set to $20 \%$, then the boiler will never turn off, resulting in wasted energy. The accurate way to model this situation is to have a 0-1 (on-off) variable to represent the boiler status, and include load range constraints in the problem. This gives the problem its integer feature. Further, boiler efficiency varies quadratically between 20 and $100 \%$ loads, giving the problem its nonlinear feature. Assuming constant or linearly varying efficiency characteristics could result in an underestimate or overestimate of optimal solutions. Hence, when developing operational planning strategies for CHP plants, the problems are inherently MINLP problems or more specifically mixed $0-1$ nonlinear programming problems since only two integers ( 0 and 1$)$ are involved. The goal of this paper is to not compromise on the integer and nonlinear aspects of the modeling procedure. These features are kept intact at all times.

The common approach to solve mixed integer programming (MIP) problems is the branch-and-bound method. It is known to cut off the global optima from the search process for nonconvex MINLP problems and more importantly suffers from the curse of dimensionality, wherein there is an exponential increase in computer processing time for a linear increase in problem size. In the last two decades genetic algorithms have made a foray in to solving many types of mathematical optimization problems. Although they can outperform deterministic algorithms for small-scale unconstrained test problems, they prove to be very ineffective when dealing with large-scale constrained problems which are often seen in real life. But when augmented with the capabilities of a deterministic algorithm, a hybrid genetic algorithm can prove to be extremely versatile in many complex optimization scenarios. Sakawa et al [1-3] showed in a series of papers how a hybrid genetic algorithm can outperform branch-and-bound for mixed 0-1 linear programming, MILP and nonlinear 0-1 programming (nonlinearities were approximated by piecewise linearities) problems. This paper shows the same for mixed 0-1 nonlinear programming (without linear approximations) problems. From an application perspective, this paper shows that MINLP models can be successfully applied to improve operational energy efficiency of CHP plants.

\section{Literature Review}

Apart from operational planning in energy systems, MIP problems are widely encountered in unit commitment/economic dispatch of thermal generators and industrial/chemical process scheduling to name just a few related engineering application domains. Interestingly, even though the problems originate in different domains, they share a great deal of similarity when it comes to modeling methodologies and computational solution techniques. Over the last five decades, significant successes have been achieved by academics around the world working in these research areas. Most research efforts can be broadly classified to be on two fronts. The first is on accurate model development to reflect the physical reality of the system under consideration. The second is towards the development of computational solution techniques seeking to solve the mathematical problems to global optimality. The following literature review is not meant to be a comprehensive account of all advances in these research areas. It reviews the most relevant papers in the context of the current work and also a few noteworthy papers which have been instrumental in guiding all research over the past years. Comprehensive reviews conducted by Saravanan et al [4], Xia and Elaiw [5], Trespalacios and Grossmann [6] and Floudas and Gounaris [7] give a chronologically accurate account of all research advances.

Cavalieri et al [8] were one of the foremost to propose the use of MIP models for operational planning in thermal power plants. They highlighted the difficulties associated with operating thermal equipment at very low loads and therefore recommended the use of $0-1$ variables to represent equipment on-off status. But they assumed boiler efficiencies to be constant in the permissible operating range, thereby making their model a mixed 0-1 linear programming one which was subsequently solved by combinatory enumeration of all possible solutions. Based on these mixed 0-1 guidelines, Logendran and Oudheusden [9] developed a model for a bi-fuel thermal power plant and found optimal solutions using the IBM/MIP solver package.

Chisman [10] was one of the foremost to deal with the problem involving multiple power plants connected to a single electric grid. For this he proposed the use of mixed 0-1 linear programming where the 0-1 variables indicated plant status rather than equipment status. The solution to the problem was obtained using a Fortran optimization routine. Gardner and Rogers [11] provided theoretical guidelines to include heat dispatch in electric dispatch problems. The resulting model for the joint planning of heat and power was a MILP model and was solved using GAMS/OSL. Makkonen and Lahdelma [12] proposed nonconvex models for such joint planning problems. The nonconvexities were converted to convexities by augmenting the model with additional constraints involving $0-1$ variables. The resulting mixed 0-1 linear programming model was solved by a customized branch-and-bound algorithm incorporating an improved simplex method which exploits the special basis structure of the problems to carry out fast inversions. Rong and Lahdelma [13] developed an envelope-based branch-and-bound technique using piecewise linear functions which performed 785 times faster than the CPLEX/MIP solver. Rong et al [14] proposed a dynamic programming (DP) algorithm based on linear relaxation of 0-1 variables and obtained solutions with low optimality gaps.

Viswanathan and Grossmann [15] developed an outer-approximation algorithm for nonconvex MINLP problems. The algorithm uses a MILP master problem that linearizes nonconvex constraints and implements a penalty function to improve solution quality. This algorithm is available as GAMS/DICOPT++. Quesada and Grossmann [16] developed a branch-and-bound algorithm for convex mixed 0-1 nonlinear programming problems. They pointed out that most computational effort is in the combinatorial search for 0-1 variables rather than in the gradient search for continuous variables. So they proposed that the nodal nonlinear programming (NLP) problems need not be solved to optimality. This led to a 50\% reduction in the number of tree nodes to be evaluated using branch-and-bound. Iyer and Grossmann [17] used 
MILP formulations for operational planning of utility plants. They developed a shortest path algorithm which guarantees global optimality and has a linear increase in CPU time for a linear increase in planning horizon size. Mitra et al [18] developed a MILP model for scheduling of a large-scale CHP plant and solved it to global optimality using GAMS/CPLEX.

Adjiman et al [19] proposed a deterministic algorithm based on branch-and-bound for finding global optimal solutions to nonconvex MINLP problems. But this method was limited to cases where integer variables appear only in linear or mixed-bilinear forms and the algorithm was tested out on small-scale problems. Leyffer [20] developed a branch-and-bound algorithm for MINLP problems in which the NLP problem at each tree node is not solved to optimality. The algorithm implements and early branching rule which helps in simultaneous execution of the tree search and the nodal NLP solution. This reduces the CPU time of the classical branch-and-bound by a factor of 3 . This algorithm is currently available as TOMLAB/MINLP. Pruitt et al [21] developed a comprehensive nonconvex MINLP modeling technique for distributed generation systems. They showed the difficulties in solving such problems to global optimality, and subsequently proposed a convex underestimation and linearization technique to solve the problem in order to use them for practical real-world applications. They used TOMLAB/MINLP and showed it to outperform BARON, Couenne, MINOTAUR-BnB, MINOTAUR-QPD and Bonmin. Pruitt et al [22] also evaluated the shortfalls of MIP models. They found that MILP models tend to overestimate optimum solutions as compared to MINLP models. Deep et al [23] developed a real coded genetic algorithm for MIP problems. This algorithm performs well for small-scale test problems and is currently available in the MATLAB/Global Optimization Toolbox. But it is not very versatile for large-scale real-world problems since it does not permit nonlinear equality constraints.

Savola et al [24] developed a MINLP model for different steam pressure levels and multi-period planning horizons and found that such models can be solved fairly accurately by the local solver GAMS/DICOPT. Tveit et al [25] analyzed a situation where heat and power generation are decoupled using thermal storage technologies to offset loads during peak production periods. The model was nonlinear and nonconvex but could be solved using GAMS/SBB. Kjeldsen and Chiarandini [26] developed heuristic approaches to the unit commitment problem with cogeneration plants. Theirs was a MILP model and the proposed heuristics were able to find solutions with 1-2\% optimality gaps. Bosman et al [27] modeled the operation of microCHP generators as integer linear programming (ILP) problems. They proposed a local search using DP and benchmarked the results using AIMMS/CPLEX. The DP solution had a 5\% loss in objective function value for a 99\% speed-up in CPU time.

The literature review helps in identifying two open research problems. First, in the context of operational planning in energy systems, there hasn't been a lot of attention given towards modeling the fundamental thermodynamic characteristics of energy conversion equipment within a CHP plant. These are nonlinear characteristics and need to be accounted for if a scheduling model is to be accurate. Second, since there isn't a theoretical proof of global optimality conditions for general nonconvex MINLP problems, there is room for improvement in developing new mathematical techniques which can produce more optimal solutions and reduce CPU time. This paper makes an effort to address these two open research problems. In the modeling aspect, it preserves all nonlinearities and nonconvexities of the plant under consideration. In the computational solution aspect, it merges the search capabilities of a stochastic technique and a deterministic technique.

\section{Scenario Description}

The scenario presented here is that of a CHP plant at a location in the Northeast US. The scenario is interesting to analyze because of its complex energy flow network and the presence of several thermodynamic equipment commonly seen in CHP plants. This leads to the creation of several linear and nonlinear energy balance equations and equipment characteristic equations, thereby producing a non-trivial problem to analyze. The methodology used to model the equations is based on the first law of thermodynamics. It can be readily adopted to model other CHP plants with similar configurations. In such cases, there will be changes in the terms and equations of the model so they reflect the configuration of that plant, but the underlying principle of the first law of thermodynamics will still govern the modeling principles. Hence the modelling methodology is universally applicable.

\subsection{Plant Structure}

Fig. 1 is a diagrammatic representation of the plant structure. The plant has a gas turbine (GT) with its exhaust being passed through a heat recovery steam generator (HRSG) equipped with a duct burner (DB). At $15^{\circ} \mathrm{C}$, the turbine has a nominal rating of $10,000 \mathrm{~kW}$, the burner $20,900 \mathrm{~kW}$ and the HRSG 40,500 kW. Electricity is also produced by a 2,000 kW high pressure steam turbine (ST1) and a 4,000 kW low pressure steam turbine (ST2). Steam is also produced by a 50,245 $\mathrm{kW}$ high pressure steam boiler (B1) and two $45,719 \mathrm{~kW}$ low pressure steam boilers (B2,B3). Plant steam is in three headers at 4,309 $\mathrm{kPa} / 393{ }^{\circ} \mathrm{C}, 1,379 \mathrm{kPa} / 241{ }^{\circ} \mathrm{C}$ and $139 \mathrm{kPa} / 135{ }^{\circ} \mathrm{C}$. Two desuperheater (DS1,DS2), each of 100,000 kW capacity help in regulating steam flows between the headers. District steam is supplied at two pressures; high pressure steam (S1) at $1,379 \mathrm{kPa} / 241^{\circ} \mathrm{C}$ and low pressure steam (S2) at $139 \mathrm{kPa} / 135^{\circ} \mathrm{C}$. The supply lines go to a nearby steam distribution building where the pressures get further regulated before actual distribution. The gas turbine and duct burner operate on natural gas whereas the boilers can be operated on natural gas or diesel oil. 


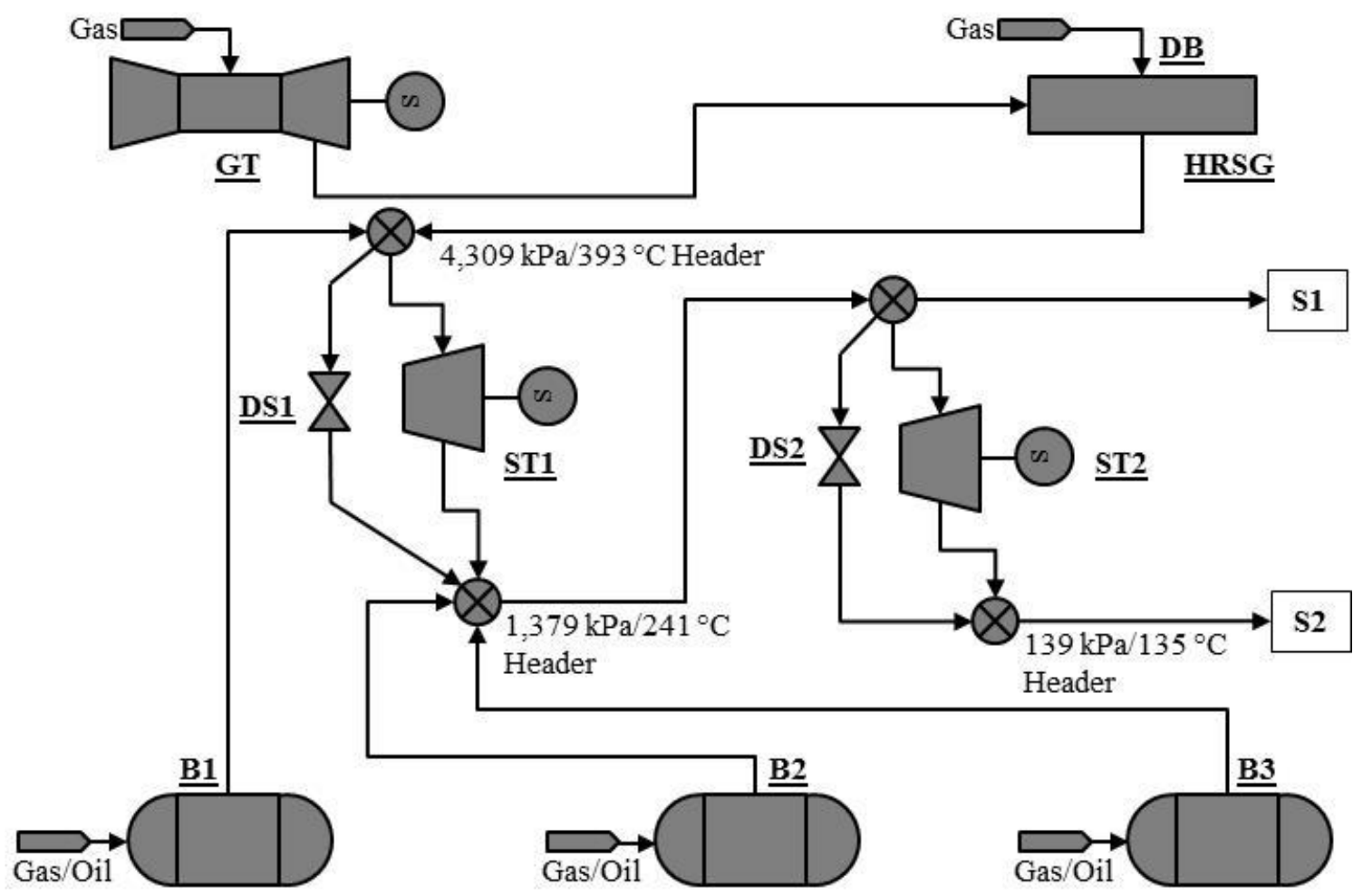

Fig. 1. Plant Structure

\subsection{Equipment Modeling}

Equipment modeling involves the use of thermodynamic performance test data to develop polynomial equations which relate inputs, outputs and efficiencies. Here, combustion characteristics of the gas turbine and boilers, heat transfer characteristics of the HRSG and mass/energy balance characteristics of the steam turbines are determined using least squares estimation on measured data.

The maximum gas turbine output varies with the ambient temperature and is given by Eqn. (1). The turbine is not allowed to operate below 50\% load. For a fixed ambient temperature, turbine thermal efficiency varies quadratically between 50\% and $100 \%$ load. Eqn. (2) gives the variation in efficiency with ambient temperature and turbine output. Fig. 2 graphically describes Eqn. (1)-(2).

$\mathrm{E}_{\mathrm{GT}}^{\max }=-15,392+238.86 \mathrm{~A}-0.5232 \mathrm{~A}^{2}$

$\eta_{\mathrm{GT}}=0.4761-2.334 \times 10^{-3} \mathrm{~A}+3.251 \times 10^{-7} \mathrm{E}_{\mathrm{GT}}+8.14 \times 10^{-8} \mathrm{AE}_{\mathrm{GT}}+3.638 \times 10^{-6} \mathrm{~A}^{2}-3.468 \times 10^{-10} \mathrm{E}_{\mathrm{GT}}^{2}$

The maximum permissible gas input to the duct burner varies with ambient temperature and gas turbine output. Eqn. (3) gives this relation. The minimum burner firing rate is $10 \%$ for any given temperature and turbine output. Ambient temperature, turbine output and burner input affect the heat transfer efficiency of HRSG as given by Eqn. (4). Table 1 is the joint characteristics of the turbine, burner and HRSG.

$\mathrm{F}_{\mathrm{DB}}^{\max }=42,620-96.66 \mathrm{~A}+0.6062 \mathrm{E}_{\mathrm{GT}}$

$\varepsilon_{\mathrm{HRSG}}=-0.103+2.7 \times 10^{-3} \mathrm{~A}+6.6538 \times 10^{-8} \mathrm{E}_{\mathrm{GT}}+1.2532 \times 10^{-5} \mathrm{~F}_{\mathrm{DB}}$

Eqn. (5)-(8) are combustion efficiency characteristics of the boilers for different fuel modes. The efficiencies are quadratic functions of the boiler outputs. The boilers are not allowed to operate below $20 \%$ load. Fig. 3 graphically describes Eqn. (5)-(8).

$$
\begin{aligned}
& \eta_{\mathrm{B} 1}^{\text {gas }}=0.7922+1.727 \times 10^{-6} \mathrm{Q}_{\mathrm{B} 1}-1.9737 \times 10^{-11} \mathrm{Q}_{\mathrm{B} 1}^{2} \\
& \eta_{\mathrm{B} 1}^{\text {oil }}=0.7632+4.3797 \times 10^{-6} \mathrm{Q}_{\mathrm{B} 1}-5.005 \times 10^{-11} \mathrm{Q}_{\mathrm{B} 1}^{2} \\
& \eta_{\mathrm{B} 2, \mathrm{~B} 3}^{\text {gas }}=0.8042+1.8851 \times 10^{-6} \mathrm{Q}_{\mathrm{B} 2, \mathrm{~B} 3}-2.3517 \times 10^{-11} \mathrm{Q}_{\mathrm{B} 2, \mathrm{~B} 3}^{2} \\
& \eta_{\mathrm{B} 2, \mathrm{~B} 3}^{\text {oil }}=0.7662+4.8378 \times 10^{-6} \mathrm{Q}_{\mathrm{B} 2, \mathrm{~B} 3}-6.1068 \times 10^{-11} \mathrm{Q}_{\mathrm{B} 2, \mathrm{~B} 3}^{2}
\end{aligned}
$$

Eqn. (9)-(10) relate the steam flows and electric outputs of the steam turbines. The steam turbines are not allowed to operate below $20 \%$ load and $\mathrm{Q}_{\mathrm{ST} 1}$ and $\mathrm{Q}_{\mathrm{ST} 2}$ are by default set to zero below that load. Fig. 4 graphically describes Eqn. (9)-(10). 


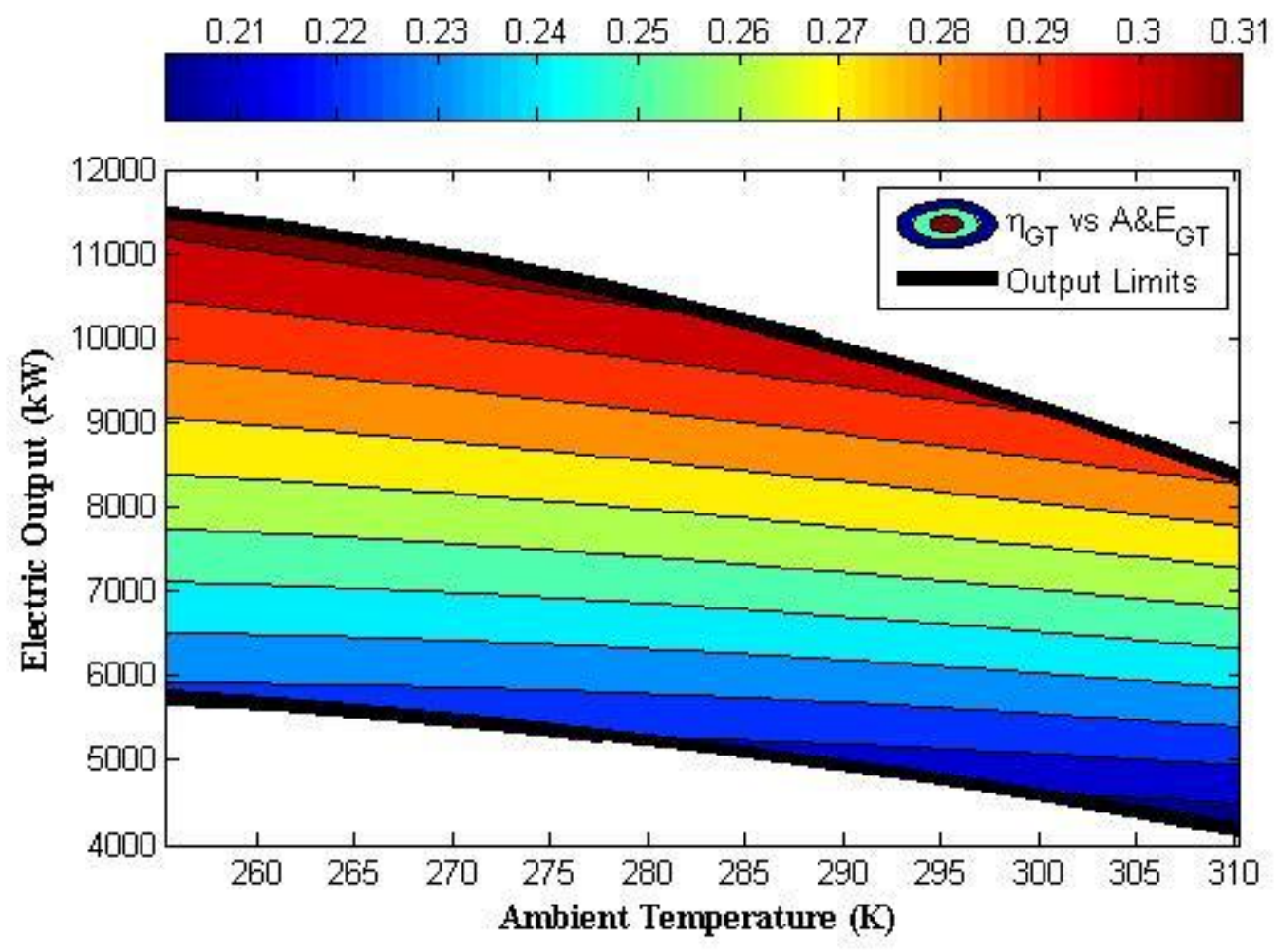

Fig. 2. Gas Turbine Characteristics

Table 1 Gas Turbine, Duct Burner and HRSG Characteristics

\begin{tabular}{|c|c|c|c|c|c|c|c|c|c|c|c|}
\hline $\mathbf{A}$ & 255 & 261 & 266 & 272 & 278 & 283 & 289 & 294 & 300 & 305 & 311 \\
\hline \multicolumn{12}{|c|}{ GT load: $100 \%$, DB firing rate: $100 \%$} \\
\hline $\mathbf{E}_{\mathrm{GT}}$ & 11,486 & 11,312 & 11,106 & 10,868 & 10,597 & 10,294 & 9,959 & 9,592 & 9,192 & 8,760 & 8,295 \\
\hline$\eta_{\mathrm{GT}}$ & 0.3141 & 0.3143 & 0.3142 & 0.3136 & 0.3125 & 0.3108 & 0.3084 & 0.3053 & 0.3014 & 0.2966 & 0.2909 \\
\hline $\mathbf{F}_{\mathrm{DB}}$ & 24,898 & 24,256 & 23,594 & 22,913 & 22,212 & 21,491 & 20,751 & 19,991 & 19,212 & 18,413 & 17,594 \\
\hline$\varepsilon_{\mathrm{HRSG}}$ & 0.8993 & 0.9062 & 0.9129 & 0.9194 & 0.9256 & 0.9315 & 0.9372 & 0.9427 & 0.9479 & 0.9528 & 0.9575 \\
\hline$\overline{Q_{\text {HRSG }}}$ & 44,951 & 44,342 & 43,668 & 42,932 & 42,138 & 41,287 & 40,382 & 39,422 & 38,409 & 37,339 & 36,211 \\
\hline \multicolumn{12}{|c|}{ GT load: $100 \%$, DB firing rate: $10 \%$} \\
\hline $\mathbf{E}_{\mathrm{GT}}$ & 11,486 & 11,312 & 11,106 & 10,868 & 10,597 & 10,294 & 9,959 & 9,592 & 9,192 & 8,760 & 8,295 \\
\hline$\eta_{\mathrm{GT}}$ & 0.3141 & 0.3143 & 0.3142 & 0.3136 & 0.3125 & 0.3108 & 0.3084 & 0.3053 & 0.3014 & 0.2966 & 0.2909 \\
\hline $\mathbf{F}_{\mathrm{DB}}$ & 2,490 & 2,426 & 2,359 & 2,291 & 2,221 & 2,149 & 2,075 & 1,999 & 1,921 & 1,841 & 1,759 \\
\hline$\varepsilon_{\text {HRSG }}$ & 0.6185 & 0.6327 & 0.6468 & 0.6609 & 0.6750 & 0.6891 & 0.7032 & 0.7172 & 0.7312 & 0.7452 & 0.7591 \\
\hline $\mathbf{Q}_{\text {HRSG }}$ & 17,055 & 17,145 & 17,204 & 17,235 & 17,238 & 17,215 & 17,165 & 17,089 & 16,986 & 16,853 & 16,686 \\
\hline \multicolumn{12}{|c|}{ GT load: $50 \%$, DB firing rate: $100 \%$} \\
\hline $\mathbf{E}_{\mathrm{GT}}$ & 5,743 & 5,656 & 5,553 & 5,434 & 5,299 & 5,147 & 4,980 & 4,796 & 4,596 & 4,380 & 4,148 \\
\hline$\eta_{\mathrm{GT}}$ & 0.2271 & 0.2257 & 0.2240 & 0.2222 & 0.2202 & 0.2180 & 0.2155 & 0.2128 & 0.2097 & 0.2063 & 0.2025 \\
\hline $\mathbf{F}_{\mathrm{DB}}$ & 21,417 & 20,827 & 20,228 & 19,619 & 19,000 & 18,371 & 17,732 & 17,084 & 16,426 & 15,758 & 15,080 \\
\hline$\varepsilon_{\text {HRSG }}$ & 0.8553 & 0.8629 & 0.8704 & 0.8777 & 0.8850 & 0.8921 & 0.8991 & 0.9059 & 0.9127 & 0.9193 & 0.9258 \\
\hline QHRSG & 35,032 & 34,719 & 34,345 & 33,911 & 33,415 & 32,857 & 32,237 & 31,552 & 30,801 & 29,980 & 29,086 \\
\hline \multicolumn{12}{|c|}{ GT load: $50 \%$, DB firing rate: $10 \%$} \\
\hline $\mathbf{E}_{\mathrm{GT}}$ & 5,743 & 5,656 & 5,553 & 5,434 & 5,299 & 5,147 & 4,980 & 4,796 & 4,596 & 4,380 & 4,148 \\
\hline & 0.2271 & 0.2257 & 0.2240 & 0.2222 & 0.2202 & 0.2180 & 0.2155 & 0.2128 & 0.2097 & 0.2063 & 0.2025 \\
\hline $\mathbf{F}_{\text {DB }}$ & 2,142 & 2,083 & 2,023 & 1,962 & 1,900 & 1,837 & 1,773 & 1,708 & 1,643 & 1,576 & 1,508 \\
\hline$\varepsilon_{\mathrm{HRSG}}$ & 0.6137 & 0.6280 & 0.6422 & 0.6565 & 0.6707 & 0.6849 & 0.6991 & 0.7132 & 0.7274 & 0.7415 & 0.7557 \\
\hline $\mathbf{Q}_{\text {HRSG }}$ & 13,308 & 13,496 & 13,651 & 13,771 & 13,855 & 13,902 & 13,909 & 13,875 & 13,795 & 13,667 & 13,486 \\
\hline
\end{tabular}




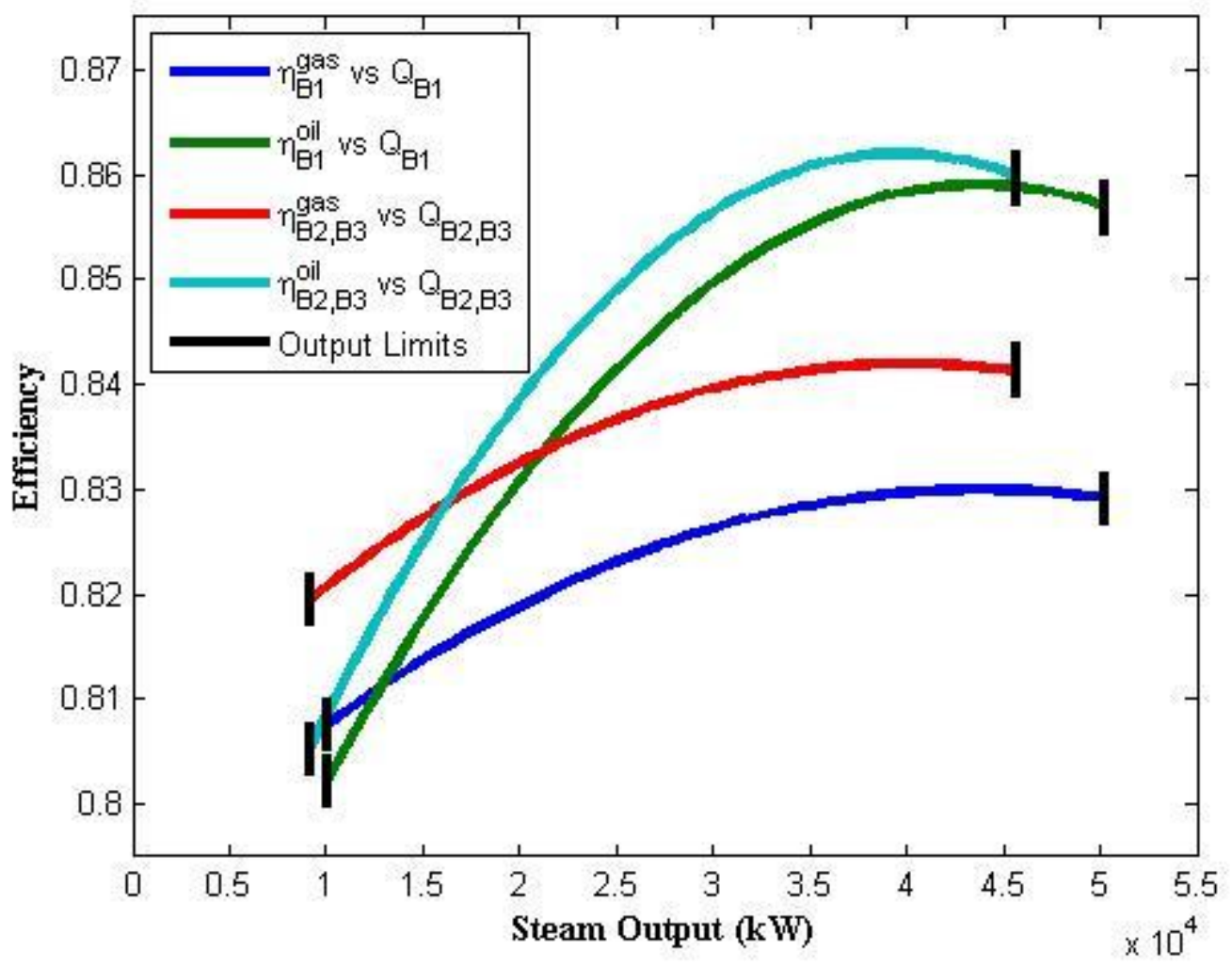

Fig. 3. Boiler Characteristics

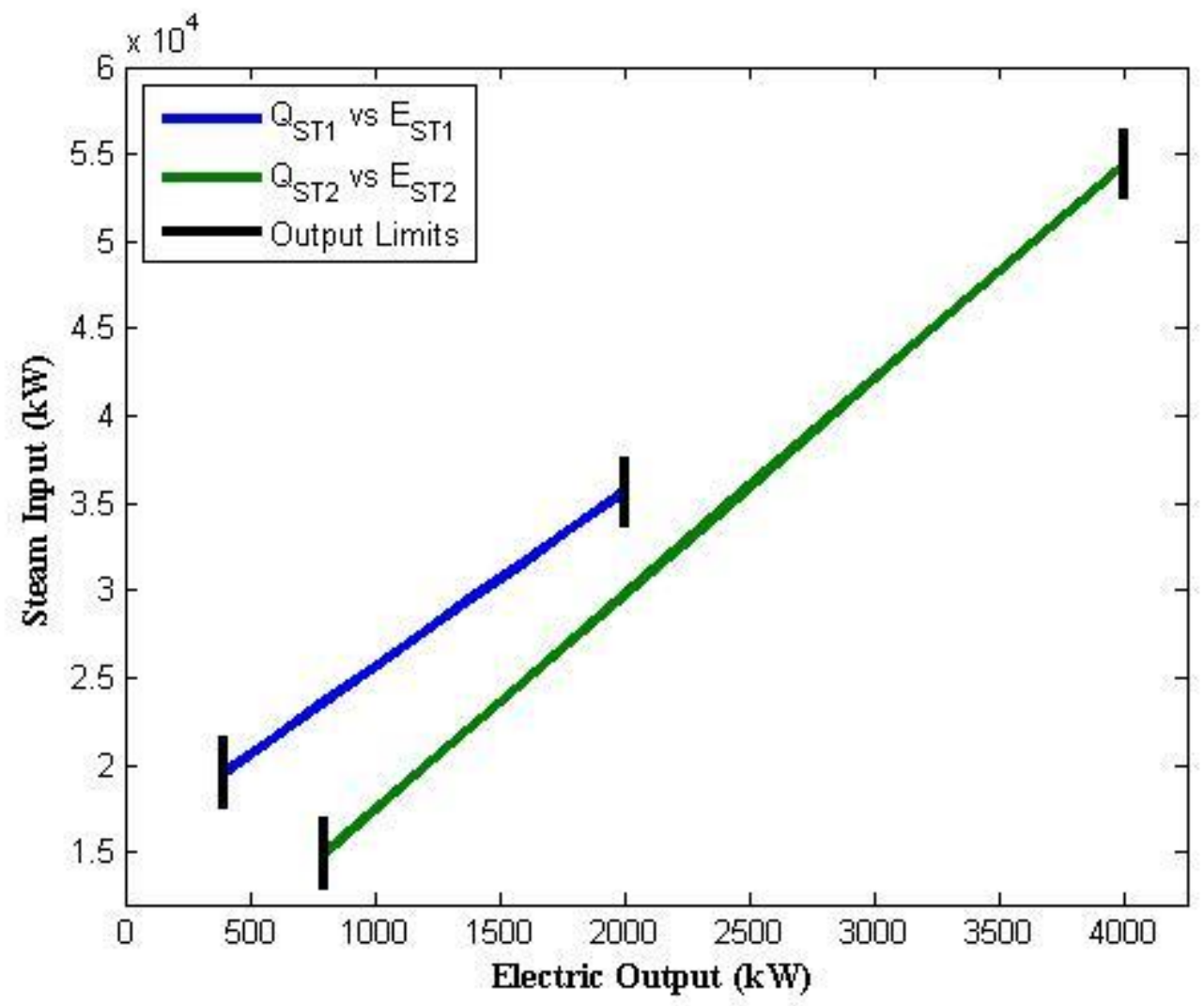

Fig. 4. Steam Turbine Characteristics 


\section{Problem Formulation}

Dotzauer [28] and Pendersen et al [29] have developed accurate techniques to forecast energy demands in district energy systems.

Given a forecast of the ambient temperature, electric demand $\left(\mathrm{E}_{\mathrm{demd}}\right)$ and steam demands $\left(\mathrm{Q}_{\mathrm{S} 1 \text { demd }}, \mathrm{Q}_{\mathrm{S} 2 \text { demd }}\right)$ for time $t$, the operational planning problem of minimizing total plant fuel consumption subject to energy demands, energy balance and equipment load range constraints is given by Problem $\mathrm{P}(\mathrm{t})$.

\section{$\underline{\text { Problem P(t) }}$}

Minimize $Z(t)=\frac{E_{G T}(t)}{\eta_{G T}(t)}+F_{D B}(t)+\frac{Q_{B 1}(t)}{\eta_{B 1}(t)}+\frac{Q_{B 2}(t)}{\eta_{B 2}(t)}+\frac{Q_{B 3}(t)}{\eta_{B 3}(t)}$

Subject to nonlinear inequality constraints (NLIC), nonlinear equality constraints (NLEC), linear inequality constraints (LIC) and variables bounds (VB):

$$
\begin{aligned}
& \operatorname{NLIC}_{1,2}(\mathrm{t}): 0.1 \mathrm{D}_{\mathrm{DB}}^{\max }(\mathrm{t}) \delta_{\mathrm{DB}}(\mathrm{t}) \leq \mathrm{F}_{\mathrm{DB}}(\mathrm{t}) \leq \mathrm{F}_{\mathrm{DB}}^{\max }(\mathrm{t}) \delta_{\mathrm{DB}}(\mathrm{t}) \\
& \operatorname{NLIC}_{3}(\mathrm{t}): \mathrm{Q}_{\mathrm{B} 2}(\mathrm{t})+\mathrm{Q}_{\mathrm{B} 3}(\mathrm{t})+\left[\mathrm{Q}_{\mathrm{ST} 1}(\mathrm{t})-\mathrm{E}_{\mathrm{ST} 1}(\mathrm{t})\right] \delta_{\mathrm{ST} 1}(\mathrm{t})+\mathrm{Q}_{\mathrm{DS} 1}(\mathrm{t})-\mathrm{Q}_{\mathrm{ST} 2}(\mathrm{t}) \delta_{\mathrm{ST} 2}(\mathrm{t})-\mathrm{Q}_{\mathrm{DS} 2}(\mathrm{t}) \geq \mathrm{Q}_{\mathrm{S} 1 \text { demd }}(\mathrm{t}) \\
& \operatorname{NLIC}_{4}(\mathrm{t}):\left[\mathrm{Q}_{\mathrm{ST} 2}(\mathrm{t})-\mathrm{E}_{\mathrm{ST} 2}(\mathrm{t})\right] \delta_{\mathrm{ST} 2}(\mathrm{t})+\mathrm{Q}_{\mathrm{DS} 2}(\mathrm{t}) \geq \mathrm{Q}_{\mathrm{S} 2 \text { demd }}(\mathrm{t}) \\
& \operatorname{NLEC}_{1}(\mathrm{t}): \varepsilon_{\mathrm{HRSG}}(\mathrm{t})=\frac{\mathrm{Q}_{\mathrm{HRSG}}(\mathrm{t})}{\frac{\mathrm{E}_{\mathrm{GT}}(\mathrm{t})}{\eta_{\mathrm{GT}}(\mathrm{t})}-\mathrm{E}_{\mathrm{GT}}(\mathrm{t})+\mathrm{F}_{\mathrm{DB}}(\mathrm{t})}
\end{aligned}
$$

$\operatorname{NLEC}_{2}(\mathrm{t}): \mathrm{Q}_{\text {HRSG }}(\mathrm{t})+\mathrm{Q}_{\mathrm{B} 1}(\mathrm{t})-\mathrm{Q}_{\mathrm{ST} 1}(\mathrm{t}) \delta_{\mathrm{ST} 1}(\mathrm{t})-\mathrm{Q}_{\mathrm{DS} 1}(\mathrm{t})=0$

$\operatorname{LIC}_{1}(\mathrm{t}): \mathrm{E}_{\mathrm{GT}}(\mathrm{t})+\mathrm{E}_{\text {ST1 }}(\mathrm{t})+\mathrm{E}_{\text {ST2 }}(\mathrm{t}) \geq \mathrm{E}_{\text {demd }}(\mathrm{t})$

$\mathrm{LIC}_{2}(\mathrm{t}): \delta_{\mathrm{DB}}(\mathrm{t}) \leq \delta_{\mathrm{GT}}(\mathrm{t})$

$\operatorname{LIC}_{3,4}(\mathrm{t}): 0.5 \mathrm{E}_{\mathrm{GT}}^{\max }(\mathrm{t}) \delta_{\mathrm{GT}}(\mathrm{t}) \leq \mathrm{E}_{\mathrm{GT}}(\mathrm{t}) \leq \mathrm{E}_{\mathrm{GT}}^{\max }(\mathrm{t}) \delta_{\mathrm{GT}}(\mathrm{t})$

$\mathrm{LIC}_{5,6}(\mathrm{t}): 0.2 \mathrm{Q}_{\mathrm{B} 1}^{\max }(\mathrm{t}) \delta_{\mathrm{B} 1}(\mathrm{t}) \leq \mathrm{Q}_{\mathrm{B} 1}(\mathrm{t}) \leq \mathrm{Q}_{\mathrm{B} 1}^{\max }(\mathrm{t}) \delta_{\mathrm{B} 1}(\mathrm{t})$

$\operatorname{LIC}_{7,8}(\mathrm{t}): 0.2 \mathrm{Q}_{\mathrm{B} 2}^{\max }(\mathrm{t}) \delta_{\mathrm{B} 2}(\mathrm{t}) \leq \mathrm{Q}_{\mathrm{B} 2}(\mathrm{t}) \leq \mathrm{Q}_{\mathrm{B} 2}^{\max }(\mathrm{t}) \delta_{\mathrm{B} 2}(\mathrm{t})$

$\mathrm{LIC}_{9,10}(\mathrm{t}): 0.2 \mathrm{Q}_{\mathrm{B} 3}^{\max }(\mathrm{t}) \delta_{\mathrm{B} 3}(\mathrm{t}) \leq \mathrm{Q}_{\mathrm{B} 3}(\mathrm{t}) \leq \mathrm{Q}_{\mathrm{B} 3}^{\max }(\mathrm{t}) \delta_{\mathrm{B} 3}(\mathrm{t})$

$\operatorname{LIC}_{11,12}(\mathrm{t}): 0.2 \mathrm{E}_{\text {ST1 }}^{\max }(\mathrm{t}) \delta_{\text {ST1 }}(\mathrm{t}) \leq \mathrm{E}_{\text {ST1 }}(\mathrm{t}) \leq \mathrm{E}_{\text {ST1 }}^{\max }(\mathrm{t}) \delta_{\text {ST1 }}(\mathrm{t})$

$\operatorname{LIC}_{13,14}(\mathrm{t}): 0.01 \mathrm{Q}_{D S 1}^{\max }(\mathrm{t}) \delta_{D S 1}(\mathrm{t}) \leq \mathrm{Q}_{D S 1}(\mathrm{t}) \leq \mathrm{Q}_{D S 1}^{\max }(\mathrm{t}) \delta_{D S 1}(\mathrm{t})$

$\operatorname{LIC}_{15,16}(\mathrm{t}): 0.2 \mathrm{E}_{\text {ST2 }}^{\max }(\mathrm{t}) \delta_{\text {ST2 }}(\mathrm{t}) \leq \mathrm{E}_{\text {ST2 }}(\mathrm{t}) \leq \mathrm{E}_{\text {ST2 }}^{\max }(\mathrm{t}) \delta_{\text {ST2 }}(\mathrm{t})$

$\mathrm{LIC}_{17,18}(\mathrm{t}): 0.01 \mathrm{Q}_{\mathrm{DS} 2}^{\max }(\mathrm{t}) \delta_{\mathrm{DS} 2}(\mathrm{t}) \leq \mathrm{Q}_{\mathrm{DS} 2}(\mathrm{t}) \leq \mathrm{Q}_{\mathrm{DS} 2}^{\max }(\mathrm{t}) \delta_{\mathrm{DS} 2}(\mathrm{t})$

$\mathrm{VB}(\mathrm{t}): 0 \leq \mathrm{x}_{\mathrm{i}}(\mathrm{t}) \leq \mathrm{x}_{\mathrm{i}}^{\max }(\mathrm{t})$ and $\delta_{\mathrm{i}}(\mathrm{t})=\{0,1\}$ where $\mathrm{x} \in[\mathrm{E}, \mathrm{F}, \mathrm{Q}]$ and $\mathrm{i} \in[\mathrm{GT}, \mathrm{DB}, \mathrm{B} 1, \mathrm{~B} 2, \mathrm{~B} 3, \mathrm{ST} 1, \mathrm{DS} 1, \mathrm{ST} 2, \mathrm{DS} 2]$

In Problem P(t), Eqn. (11) is the expression for plant fuel consumption. Eqn. (12) is the load range constraint for the duct burner. Eqn. (13) is a composite energy balance and steam demand constraint in the $1,379 \mathrm{kPa} / 241{ }^{\circ} \mathrm{C}$ header. Eqn. (14) is a composite energy balance and steam demand constraint in the $139 \mathrm{kPa} / 135^{\circ} \mathrm{C}$ header. Eqn. (15) is a composite energy balance and equipment characteristic constraint for the HRSG. Eqn. (16) is the energy balance constraint for the $4,309 \mathrm{kPa} / 393{ }^{\circ} \mathrm{C}$ header. Eqn. (17) is the electric demand constraint. Eqn. (18) is the constraint requiring the duct burner be operated only when the gas turbine is operated. Eqn. (19)-(26) are equipment load range constraints. Eqn. (27) gives the bounds for the continuous variables (CV) and binary variables (BV) in the problem.

Problem $\mathrm{P}(\mathrm{t})$ involves 10 continuous variables, 9 binary variables, 4 nonlinear inequality constraints, 2 nonlinear equality constraints and 18 linear inequality constraints. It is a small-scale mixed 0-1 nonlinear programming problem. Typically for $t, 1$ hour time-steps are used with the assumption of steady-state operating conditions during the hour. The goal is to have plans available for prolonged periods of operation. 
But if separate Problem $\mathrm{P}(\mathrm{t})$ are solved for each hour over the planning horizon and their solutions are merged, then frequent equipment start/stop will occur leading to energy waste. To overcome this, a multi-period problem incorporating minimization of equipment start/stop is given by Problem $\mathrm{P}(\mathrm{t}, \mathrm{T})$.

\section{$\underline{\text { Problem P(t,T) }}$}

$$
\operatorname{Minimize} \sum_{\tau=t}^{\tau=t+T-1}\left[Z(\tau)+\sum_{i \in I} \phi_{i}\left|\delta_{i}(\tau)-\delta_{i}(\tau-1)\right|\right]
$$

Subject to constraints and bounds

$$
\operatorname{NLIC}_{\mathrm{n}}(\tau), \operatorname{NLEC}_{\mathrm{m}}(\tau), \operatorname{LIC}_{\mathrm{o}}(\tau) \text { and } \operatorname{VB}(\tau) \text { where } \mathrm{n} \in[1,4], \mathrm{m} \in[1,2], \mathrm{o} \in[1,18] \text { and } \tau \in[\mathrm{t}, \mathrm{t}+\mathrm{T}-1]
$$

In Problem $\mathrm{P}(\mathrm{t}, \mathrm{T}), \mathrm{T}$ is number of hours in the planning horizon and $\phi$ are the one-time equipment start/stop energy usage. Eqn. (28) is the expression for total plant fuel consumption over the planning horizon, which is the sum of hourly fuel consumptions and total energy used for all start/stop of equipment occurring during the horizon. The problem is subject to hourly energy demands, energy balance and equipment load range constraints as given by Eqn. (29). This is a large-scale mixed 0-1 nonlinear programming problem and the problem size depends on the number of hours in the planning horizon.

\section{Proposed Genetic Algorithm}

Sakawa et al [1] presented a unique genetic algorithm method to solve mixed 0-1 linear programming problems. In their method, 0-1 variables are determined by genetic algorithms and continuous variables are determined by solving linear programming problems obtained on fixing 0-1 variable values. This is a bi-level method wherein the upper level involves a single unconstrained stochastic combinatorial optimization problem and the lower level involves several constrained deterministic linear programming problems. This method is extended to solve Problem $\mathrm{P}(\mathrm{t}, \mathrm{T})$, wherein the lower level will involve several constrained deterministic NLP problems.

\subsection{Genetic Individual}

Fig. 5 depicts a genetic individual for Problem $\mathrm{P}(\mathrm{t}, \mathrm{T})$. An individual is formed by connecting sub-individuals which consist of 0-1 variables corresponding to on-off status of equipment at each hour over the planning horizon.

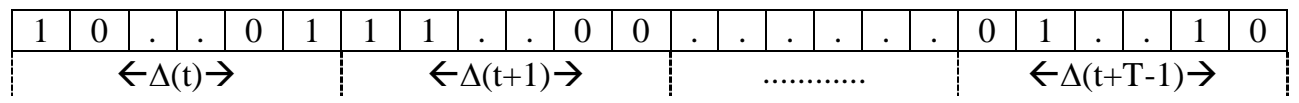

Fig. 5. Genetic Individual

\subsection{Generation of Initial Population}

In order for the evolution to proceed effectively, the initial population though generated randomly must consist only of feasible individuals. This is done by randomly generating 0-1 values for each hour in the planning horizon. The 0-1 values are then used in the corresponding Problem $\mathrm{P}(\mathrm{t})$ to reduce it to an NLP problem for the given hour. The reduced problem is solved using a sequential quadratic programming (SQP) solver. If the problem is feasible then the 0-1 values are considered in the initial population, else the procedure is repeated until a feasible individual is found. The following is the pseudocode to generate a feasible initial population.

\section{Pseudocode for generation of initial population}

Begin

for $\mathrm{n}=1$ to population size

for $\mathrm{t}=1$ to planning horizon size

flag $=0$;

do while flag $<1$

randomly generate 9 bit 0-1 string;

use string in Problem P(t) and reduce it to NLP problem in 10 continuous variables;

use SQP solver on NLP problem; 
if problem is feasible then

assign string to $\Delta(\mathrm{t})$ of genetic individual $\mathrm{n}$;

flag $=1$;

end if

end do while

end for

end for

End

\subsection{Fitness Evaluation}

In Problem $\mathrm{P}(\mathrm{t}, \mathrm{T})$, the term that connects subsequent hours in the planning horizon is the term associated with the total start/stop energy in the objective function. For the genetic individuals in the population, this term can be directly evaluated and does not require any solving. This makes it possible to detach subsequent hours of the planning horizon and solve each hour separately to find hourly solutions. If all hourly NLP problems are feasible, then the fitness of the individual is determined by summing the objective function values of the hourly NLP problems and adding the scalar value of the total start/stop energy term. If any hourly NLP problem is infeasible, then the individual is assigned a very high fitness value (problem is in minimization form, hence individuals with low objective function values are fitter than individuals with high objective function values) with the intention that it will die out in the evolutionary process. The novelty of this solution technique is that it eliminates the curse of dimensionality by solving for the continuous variables in each hour independent of subsequent hours and directly evaluating the term which contains binary variables spanning over the planning horizon. The following is the pseudocode for fitness evaluation.

\section{Pseudocode for fitness evaluation}

\section{Begin}

number of start/stop $=0$;

for $i=1$ to number of equipment

for $\mathrm{t}=2$ to planning horizon size

number of start/stop $=$ number of start/stop $+\left|\delta_{\mathrm{i}}(\mathrm{t})-\delta_{\mathrm{i}}(\mathrm{t}-1)\right|$;

\section{end for}

\section{end for}

total start/stop energy $=[$ number of start/stop $] x[$ start/stop energy $]$;

fitness $=0$;

flag $=0$;

for $\mathrm{t}=1$ to planning horizon size

use $\Delta(\mathrm{t})$ in Problem $\mathrm{P}(\mathrm{t})$ and reduce it to NLP problem in 10 continuous variables;

use SQP solver on NLP problem;

if problem is feasible then

fitness $=$ fitness + objective function value;

else if problem is infeasible then

flag $=1$;

end if

end for

if flag is 0 then 
fitness $=$ fitness + total start/stop energy;

else if flag is 1 then

fitness $=\infty$;

end if

End

\subsection{Scaling}

Fitness scaling is done in order to convert the range of raw fitness values to a range more suitable for the selection procedure. Here linear scaling and ranked scaling will be used for experimentation.

Linear scaling: The raw fitness value $f$ of an individual is converted to a scaled fitness value $f_{s}$ according to the relation $f_{s}=a f+b$. The coefficients $a$ and $b$ are determined based on the mean, maximum and minimum fitness in the population.

Ranked scaling: The individual with the best fitness in the population is assigned rank 1 and the individual with the worst fitness is assigned rank N. All other individuals are sorted according to their raw fitness values and assigned ranks from 2 to N-1.

\subsection{Selection}

Selection involves picking individuals to fill the mating pool to create off-springs of the next generation. Here roulette wheel selection, tournament selection and stochastic uniform selection will be used for experimentation.

Roulette wheel selection: The individuals get assigned portions of a roulette wheel proportional to their scaled fitness values. The wheel is then spun $\mathrm{N}$ times (once for each individual), which is to say a random number between 0 and 1 is drawn $\mathrm{N}$ times. Using the drawn random number and the sum of the scaled fitness values of the whole population, an appropriate individual gets picked to go in to the mating pool.

Tournament selection: Two or more individuals are chosen at random to play in a tournament. The tournament involves comparing the scaled fitness values. The individual with the best scaled fitness value is picked to go in to the mating pool.

Stochastic uniform selection: Individuals get assigned portions of a line according to their scaled fitness values. A selector moves over the line in equal step sizes from a randomly chosen starting point. The individuals corresponding to the portions of the line on which the selector lands are picked to go in to the mating pool.

\subsection{Crossover}

Crossover involves randomly choosing two individuals from the mating pool and creating off-springs of the next generation. Here one-point crossover, two-point crossover and scattered crossover will be used for experimentation.

One-point crossover: After randomly choosing two individuals for mating, a crossover point is determined, which could be at any location along the bit string of the individuals. The binary sub-strings to one side of the crossover point are exchanged between the mating individuals to create off-springs.

Two-point crossover: After randomly choosing two individuals for mating, two crossover points are determined, which are at different locations along the bit string of the individuals. The binary sub-strings to one side of both crossover points are exchanged between the mating individuals to create off-springs.

Scattered crossover: After randomly choosing two individuals for mating, a random binary string the same size of the individuals is first created. Moving bitwise in the newly created string, if the bit value is 1 then the gene corresponding to first individual is taken, and if the bit value is 0 then the gene corresponding to the second individual is taken to create an off-spring.

\subsection{Mutation}

Mutation involves random changes to an individual to create off-springs. Here uniform mutation and Gaussian mutation will be used for experimentation.

Uniform mutation: Some of the bits of an individual are randomly chosen for mutation with each chosen bit having a specified mutation probability. A random binary digit is then drawn from a uniform distribution. Depending on the mutation probability, the bit is either replaced or left unaffected.

Gaussian mutation: Moving bitwise along an individual, a random number drawn from a Gaussian distribution with 0 mean is added to each bit. If the new bit value is not binary, then it is clipped to the nearest binary digit. 


\section{Numerical Experiments}

Numerical experiments are carried out in MATLAB on a desktop PC with a $3.1 \mathrm{GHz}$ quad-core processor, 8 GB RAM and 64-bit Microsoft Windows 7 Professional operating system. In practice, operational planning can be done only if there are forecasts available for ambient temperature and energy demands. But this paper does not involve forecasting techniques. It verifies proof-of-concepts of the optimization aspects given forecasted temperatures and demands. For such verification experiments historical data can be used. Hence, hourly operational data for 24-hour periods are gathered for analysis. The data is from the year 2012 and is given in the appendix. Hour 1 is from 12 PM to 1 PM and Hour 24 is from 11 AM to 12 PM the following day. Total plant electric and steam output during these periods are used in energy demand constraints. Since plant steam output can be sent by either supply line to the steam distribution building, in the experimental setup the total steam demand is equally split between the two lines. Although the start/stop energy are different for the equipment, in a CHP setting when any equipment is switched on or off, it usually causes the load on some other equipment to be adjusted. Hence, for experimental purposes an average value of $10,000 \mathrm{kWh} / \mathrm{switch}$ is used for all $\phi$. The experiments will indicate if there could have been a more energy efficient operational plan for the periods under consideration. In the following discussions PR, BB and GA indicate present schedule, branchand-bound schedule and genetic algorithm schedule respectively.

TOMLAB/MINLP [30] is used for BB. The function that does the tree search is minlpBB and the function that solves the nodal NLP problems is the SQP solver filter $S Q P$. filter $S Q P$ can by itself be called to solve any NLP problem. For GA, the genetic procedures on $0-1$ variables are carried out using the $g a$ function in MATLAB/Global Optimization Toolbox [31] and filterSQP is used to solve NLP problems used in determining fitness of individuals. The population size is 50 and elite preserving allows the fittest individual to proceed directly to the next generation. The evolution terminates when the fittest individual in the population is not updated for 50 successive generations or the evolution reaches a maximum of 500 generations. These parameters are determined by trial-and-error before starting the numerical experiments and are not altered during the experiments. Three combinations of scaling, selection, crossover and mutation are used in the experiments; GA' - linear scaling, roulette wheel selection, one-point crossover, uniform mutation; GA" - linear scaling, tournament selection, two-point crossover, uniform mutation; GA" " - ranked scaling, stochastic uniform selection, scattered crossover, Gaussian mutation. Following standard practice when experimenting with genetic algorithms, 10 trials are done in all cases. Three planning horizon sizes (6, 12 and 24 hours) are considered which set up three problems; $\mathrm{P}(\mathrm{t}, 6), \mathrm{P}(\mathrm{t}, 12)$ and $\mathrm{P}(\mathrm{t}, 24)$. Table 2 gives the number of problem variables and constraints for the three planning horizon sizes.

Table 2 Problem Dimensions

\begin{tabular}{|c|c|c|c|c|c|c|}
\hline Problem & $\begin{array}{c}\text { Planning } \\
\text { Horizon }\end{array}$ & \# CV & \# BV & \# NLIC & \# NLEC & \# LIC \\
\hline $\mathrm{P}(\mathrm{t}, 6)$ & 6 hours & 60 & 54 & 24 & 12 & 108 \\
\hline $\mathrm{P}(\mathrm{t}, 12)$ & 12 hours & 120 & 108 & 48 & 24 & 216 \\
\hline $\mathrm{P}(\mathrm{t}, 24)$ & 24 hours & 240 & 216 & 96 & 48 & 432 \\
\hline
\end{tabular}

\subsection{Experiment 1}

Experiment 1 considers the coldest 24-hour period to occur in the month of January at the plant location. This period is of interest to analyze because the steam demand on the plant is the highest during the year. At such times due to energy market dynamics at the plant location, natural gas is available only in limited quantities. So the plant uses gas only in the gas turbine and duct burner and uses diesel oil in the boilers. When setting up the experiments, the boiler efficiency equations for oil are used. The average ambient temperature over the 24-hour period is around $-12{ }^{\circ} \mathrm{C}$ which results in the nominal rating of the gas turbine, duct burner and HRSG to be in the range of $11,300 \mathrm{~kW}, 24,200$ $\mathrm{kW}$ and 44,300 kW, respectively. Precise nominal ratings are used when setting up the experiment using hourly ambient temperatures. Table A1 in the appendix shows the hourly recorded ambient temperature and total electric and steam demands. The temperature and demands are used in setting up the experiment.

Problem $\mathrm{P}(\mathrm{t}, 6)$ involves the first 6 hours, $\mathrm{P}(\mathrm{t}, 12)$ involves the first 12 hours and $\mathrm{P}(\mathrm{t}, 24)$ involves all 24 hours. The results of the experiment are given in Table 3. LB is the lower bound on the objective function obtained by relaxing the integrality restrictions and solving the resulting NLP problem using filter $S Q P$. $\mathrm{BB}(\mathrm{T})$ is the solution by $\mathrm{BB}$ for planning horizon size $\mathrm{T}$ and $\mathrm{BB}(1)$ is the solution for the same planning horizon by BB but solving each hourly problem independently by ignoring continuity of equipment operation. The rest of the table is the solutions obtained by GA.

For Problem $\mathrm{P}(\mathrm{t}, 6), \mathrm{BB}(\mathrm{T})$ produces an integer feasible solution in about 1 minute as the problem size is not very large. But solutions found in Trials 3, 7 and 10 of GA" " are more optimal than that of $\mathrm{BB}(\mathrm{T})$. This result is indicative of the nonconvexity of the problem, wherein the global minimum is unknown. The way to compare the search capabilities of the two solution techniques is to see which one produces a solution with lower objective function value. But the average CPU time for GA' is 658 seconds, for GA" is 511 seconds and for GA" " is 528 seconds which are 8 times greater than that of $\mathrm{BB}(\mathrm{T})$. And since $\mathrm{BB}(\mathrm{T})$ solution is obtained in this case, $\mathrm{BB}(1)$ solution is not needed. For Problem $\mathrm{P}(\mathrm{t}, 12), \mathrm{BB}(\mathrm{T})$ produces an integer feasible solution in about 7 minutes and $\mathrm{BB}(1)$ solution is not needed. But solutions found in Trials 3 and 8 of GA" " are more optimal than that of $\mathrm{BB}(\mathrm{T})$. The average CPU time for GA' is 2,277 seconds, for GA" is 2,314 seconds and for GA" " is 2,055 seconds which are only 4 times greater than that of $\mathrm{BB}(\mathrm{T})$. The relative increase in CPU time of GA is less than that of BB(T) when the planning horizon is doubled. For Problem $\mathrm{P}(\mathrm{t}, 24), \mathrm{BB}(\mathrm{T})$ takes about 27 minutes but reports an integer infeasible solution. This means after solving the root NLP problem in the BB tree, the addition of new integrality constraints caused the resulting nodal NLP problems 
to be infeasible. Since no integer feasible solution is found, it means no upper bound to the problem is found. The upper bound in BB is an important parameter to carry out the tree search process. In this case BB had to terminate without an integer feasible solution or an upper bound. Hence, in order to have an operational plan, the hourly problems ignoring continuity of equipment operation are solved. This solution is given by $\mathrm{BB}(1)$ and it takes only about 7 seconds to solve 24 hourly Problem $\mathrm{P}(\mathrm{t})$ by $\mathrm{BB}$. On the other hand, GA finds several unique solutions for Problem $\mathrm{P}(\mathrm{t}, 24)$. The solution found in Trial 6 of GA' "' is the most optimum. The average processing time for GA' is 6,428 seconds, for GA" is 6,681 seconds and for GA"' is 6,112 seconds.

Fig. 6 compares the binary variable values of PR and those obtained by BB (BB(1) from P(t,24)) and GA (Trial 6 of GA" from $\mathrm{P}(\mathrm{t}, 24))$. In the figure, grey lines mean equipment is operated. The corresponding continuous variable values (equipment loads) are given in Table A2 in the appendix. In PR all plant equipment were operated which resulted in them being at part-load conditions and also there were 3 start/stops. BB also operates all equipment and is much worse since there are 22 start/stops. This is because BB(1) ignores continuity of equipment operation for subsequent hours in the horizon. GA operates only the least number of equipment at any given time to meet the energy demands. But because of the random nature of GA, it contains 4 start/stops. Table 8 summarizes the plant performance for the three schedules being compared. PR resulted in the present plant energy efficiency to be $81.75 \%$. BB reduces the efficiency to $80.10 \%$. GA increases the efficiency to $86.87 \%$ since only the least number of equipment are operated, allowing them to be near full-load conditions. GA leads to a 5\% increase in efficiency while still satisfying all energy demands and equipment load range constraints.

Table 3 Experiment 1 Results

\begin{tabular}{|c|c|c|c|c|c|c|}
\hline & \multicolumn{2}{|c|}{$\mathbf{P}(\mathbf{t}, \mathbf{6})$} & \multicolumn{2}{|c|}{$\mathbf{P}(\mathbf{t}, \mathbf{1 2})$} & \multicolumn{2}{|c|}{$\mathbf{P}(\mathbf{t}, \mathbf{2 4})$} \\
\hline & $\begin{array}{c}\text { Obj. Func. } \\
\text { (kWh) }\end{array}$ & $\begin{array}{c}\text { CPU Time } \\
\text { (s) }\end{array}$ & $\begin{array}{c}\text { Obj. Func. } \\
\text { (kWh) }\end{array}$ & $\begin{array}{c}\text { CPU Time } \\
\text { (s) }\end{array}$ & $\begin{array}{c}\text { Obj. Func. } \\
\text { (kWh) }\end{array}$ & $\begin{array}{c}\text { CPU Time } \\
\text { (s) }\end{array}$ \\
\hline LB & 579,515 & - & $1,168,312$ & - & $2,481,018$ & - \\
\hline $\mathbf{B B}(\mathrm{T})$ & 584,934 & 64 & $1,180,521$ & 439 & $\mathrm{x}$ & 1,662 \\
\hline BB(1) & - & - & - & - & $2,729,126$ & 7.13 \\
\hline \multicolumn{7}{|c|}{ GA' $^{\prime}$} \\
\hline Trial 1 & 597,939 & 840 & $1,238,517$ & 2,805 & $3,003,625$ & 4,664 \\
\hline Trial 2 & 611,612 & 470 & $1,237,863$ & 2,245 & $2,686,522$ & 7,929 \\
\hline Trial 3 & 590,672 & 809 & $1,216,871$ & 4,003 & $2,682,547$ & 7,974 \\
\hline Trial 4 & 605,509 & 442 & $1,217,115$ & 3,172 & $2,742,112$ & 8,011 \\
\hline Trial 5 & 597,225 & 747 & $1,242,565$ & 3,541 & $3,073,350$ & 1,269 \\
\hline Trial 6 & 595,806 & 1,090 & $1,218,262$ & 1,904 & $2,722,911$ & 7,917 \\
\hline Trial 7 & 584,934 & 767 & $1,266,392$ & 1,324 & $2,678,386$ & 6,882 \\
\hline Trial 8 & 598,237 & 463 & $1,257,119$ & 1,470 & $2,677,900$ & 8,028 \\
\hline Trial 9 & 598,425 & 331 & $1,321,408$ & 839 & $2,720,815$ & 5,045 \\
\hline Trial 10 & 611,213 & 619 & $1,264,786$ & 1,471 & $2,746,795$ & 6,562 \\
\hline \multicolumn{7}{|c|}{$\mathbf{G A}^{\prime \prime}$} \\
\hline Trial 1 & 598,425 & 365 & $1,219,189$ & 2,798 & $2,827,412$ & 5,117 \\
\hline Trial 2 & 588,109 & 665 & $1,232,659$ & 2,161 & $2,745,325$ & 7,936 \\
\hline Trial 3 & 594,684 & 732 & $1,257,027$ & 1,591 & $2,741,228$ & 5,768 \\
\hline Trial 4 & 589,302 & 549 & $1,225,380$ & 2,647 & $2,775,897$ & 6,542 \\
\hline Trial 5 & 596,055 & 593 & $1,206,666$ & 1,110 & $2,793,714$ & 6,838 \\
\hline Trial 6 & 600,292 & 378 & $1,213,086$ & 2,466 & $2,893,961$ & 3,025 \\
\hline Trial 7 & 598,425 & 351 & $1,243,059$ & 1,925 & $2,710,919$ & 7,838 \\
\hline Trial 8 & 595,979 & 383 & $1,211,801$ & 1,926 & $2,719,695$ & 7,884 \\
\hline Trial 9 & 605,034 & 574 & $1,221,472$ & 3,297 & $2,756,167$ & 7,915 \\
\hline Trial 10 & 597,225 & 522 & $1,229,302$ & 3,216 & $2,679,349$ & 7,949 \\
\hline \multicolumn{7}{|c|}{ GA'"' } \\
\hline Trial 1 & 597,225 & 433 & $1,195,729$ & 1,824 & $2,534,219$ & 6,272 \\
\hline Trial 2 & 601,252 & 513 & $1,186,495$ & 2,466 & $2,516,414$ & 5,019 \\
\hline Trial 3 & 583,531 & 629 & $1,174,745$ & 2,331 & $2,595,231$ & 4,281 \\
\hline Trial 4 & 589,302 & 549 & $1,186,434$ & 2,028 & $2,621,353$ & 6,579 \\
\hline Trial 5 & 590,672 & 317 & $1,201,103$ & 1,993 & $2,524,330$ & 6,696 \\
\hline Trial 6 & 590,672 & 411 & $1,242,682$ & 2,003 & $2,512,828$ & 6,530 \\
\hline Trial 7 & 582,146 & 772 & $1,186,434$ & 1,772 & $2,541,763$ & 6,550 \\
\hline Trial 8 & 589,507 & 654 & $1,174,787$ & 2,683 & $2,532,972$ & 6,829 \\
\hline Trial 9 & 591,630 & 452 & $1,199,143$ & 1,716 & $2,527,719$ & 6,468 \\
\hline Trial 10 & 580,775 & 547 & $1,192,808$ & 1,735 & $2,525,340$ & 5,897 \\
\hline
\end{tabular}



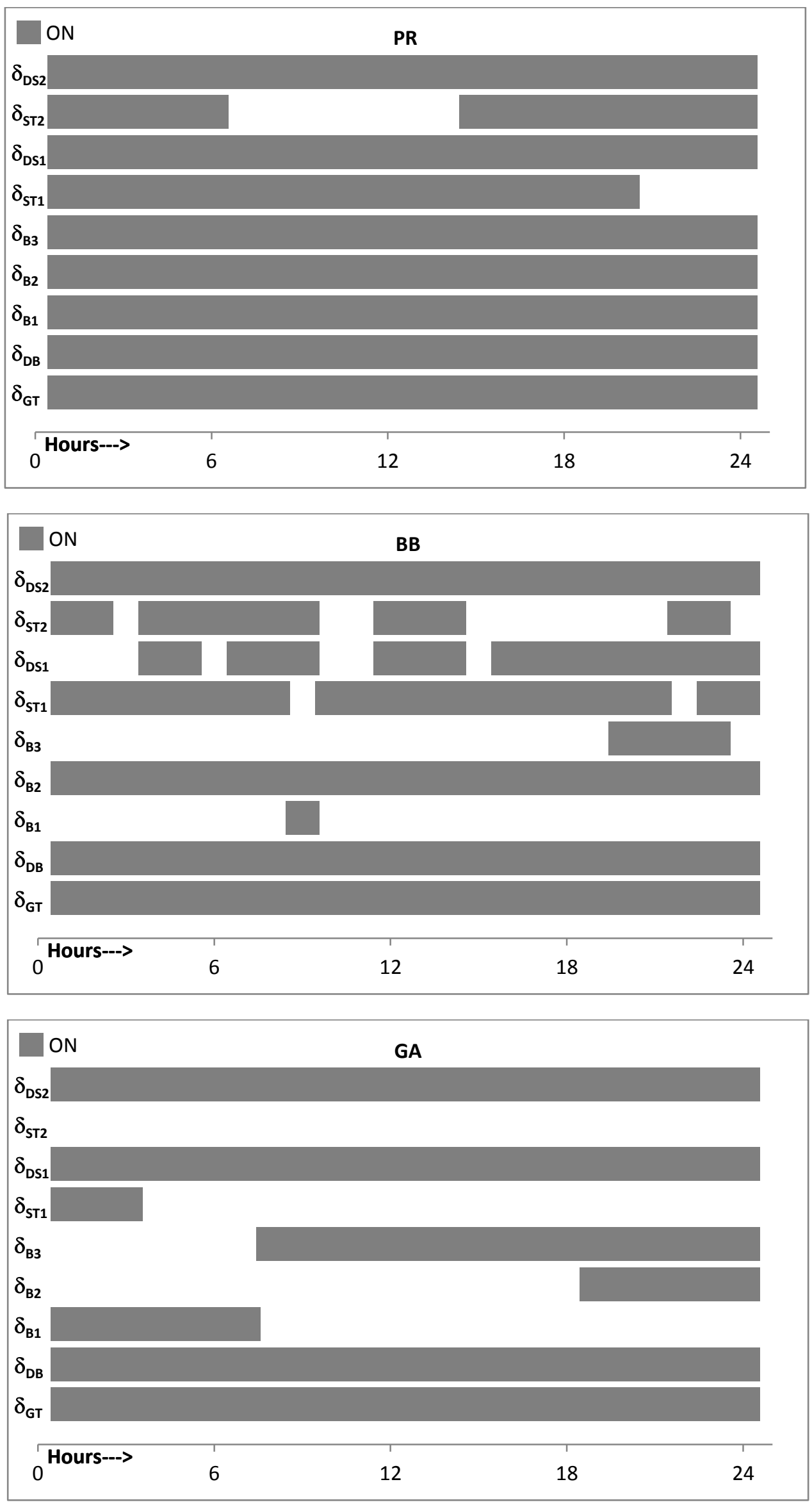

Fig. 6. Experiment 1 Binary Variables 


\subsection{Experiment 2}

Experiment 2 considers a 24-hour period occurring in the month of April which is during the Spring season. This period is of interest to analyze because the steam demand begins to drop as winter recedes and summer approaches. Two boilers (B1,B2) are run on oil whereas the third boiler (B3) if needed is run on gas. When setting up the experiments, the appropriate efficiency equation for each boiler is used. The average ambient temperature over the 24-hour period is around $-1{ }^{\circ} \mathrm{C}$ which results in the nominal rating of the gas turbine, duct burner and HRSG to be in the range of $10,900 \mathrm{~kW}, 22,900 \mathrm{~kW}$ and $42,900 \mathrm{~kW}$, respectively. Table A1 in the appendix shows the hourly recorded ambient temperature and total electric and steam demands.

The summary of the experiment results are given in Table 4. For Problem $\mathrm{P}(\mathrm{t}, 6), \mathrm{BB}(\mathrm{T})$ produces an integer feasible solution in under 1 minute and $\mathrm{BB}(1)$ solution is not needed. But the best solutions found by GA" and GA", are more optimal than that of BB(T). Interestingly, the best solution of GA" "is lower than LB. This is because the relaxed NLP problem which gives LB is a nonconvex problem. Hence, LB is a local minimum to the relaxed problem. There can exist integer feasible solutions with objective function values lesser than LB but greater than the global minimum of the relaxed problem. GA" " captures one such integer feasible solution lying between LB and the global minimum. For Problem $\mathrm{P}(\mathrm{t}, 12), \mathrm{BB}(\mathrm{T})$ produces an integer feasible solution in less than 5 minutes and $\mathrm{BB}(1)$ solution is not needed. None of the GA trials find better solutions than that of $\mathrm{BB}(\mathrm{T})$. For Problem $\mathrm{P}(\mathrm{t}, 24), \mathrm{BB}(\mathrm{T})$ takes about 21 minutes but reports an integer infeasible solution. Hence, $\mathrm{BB}(1)$ problems are solved and it takes less than 2 seconds to obtain the solution to 24 hourly Problem $\mathrm{P}(\mathrm{t})$ by $\mathrm{BB}$. GA finds several unique solutions to Problem $\mathrm{P}(\mathrm{t}, 24)$ of which the best one found by GA" "' is the most optimum. For Problem $\mathrm{P}(\mathrm{t}, 6)$ the average CPU time for GA' is 602 seconds, for GA" is 508 seconds and GA " ' is 503 seconds. For Problem P(t,12) the average CPU time for GA' is 2,060 seconds, for GA" is 1,688 seconds and GA" " is 1,576 seconds. For Problem P(t,24) the average CPU time for GA' is 7,010 seconds, for GA" is 6,673 seconds and $\mathrm{GA}^{\prime \prime}$ " is 4,434 seconds.

The continuous variable values corresponding to PR, BB(1) and the best GA'”, are given in Table A2 in the appendix. In PR steam was produced by the HRSG and two boilers which were run on oil and 1 start/stop occurred in the duct burner of the HRSG. GA identifies that it is better to increase the output from the HRSG by making full use of the duct burner capacity. Table 8 summarizes the plant performance for the three schedules. PR resulted in the present plant energy efficiency to be $78.78 \%$. BB reduces the efficiency to $68.35 \%$. and has 47 start/stops. Even though GA contains 4 start/stops it increases the efficiency to $88.41 \%$ because it operates the equipment at higher loads. GA leads to a $10 \%$ increase in efficiency.

Table 4 Experiment 2 Results Summary

\begin{tabular}{|c|c|c|c|c|c|c|}
\hline & \multicolumn{2}{|c|}{$\mathbf{P}(\mathbf{t}, \mathbf{6})$} & \multicolumn{2}{|c|}{$P(t, 12)$} & \multicolumn{2}{|c|}{$\mathbf{P}(\mathbf{t}, 24)$} \\
\hline & $\begin{array}{c}\text { Obj. Func. } \\
\text { (kWh) }\end{array}$ & $\begin{array}{c}\text { CPU Time } \\
\text { (s) }\end{array}$ & $\begin{array}{c}\text { Obj. Func. } \\
\text { (kWh) }\end{array}$ & $\begin{array}{c}\text { CPU Time } \\
\text { (s) }\end{array}$ & $\begin{array}{c}\text { Obj. Func. } \\
\text { (kWh) }\end{array}$ & $\begin{array}{c}\text { CPU Time } \\
\text { (s) }\end{array}$ \\
\hline LB & 414,073 & - & 883,713 & - & $1,813,375$ & - \\
\hline $\mathbf{B B}(\mathbf{T})$ & 417,001 & 52 & 894,646 & 253 & $\mathrm{x}$ & 1,316 \\
\hline BB(1) & - & - & - & - & $2,887,093$ & 1.66 \\
\hline \multicolumn{7}{|c|}{ GA' $^{\prime}$} \\
\hline Best & 417,001 & \multirow{5}{*}{$\begin{array}{c}602 \\
\text { (avg) }\end{array}$} & 959,261 & \multirow{5}{*}{$\begin{array}{l}2,060 \\
\text { (avg) }\end{array}$} & $2,031,076$ & \multirow{5}{*}{$\begin{array}{l}7,010 \\
\text { (avg) }\end{array}$} \\
\hline Average & 434,212 & & 991,933 & & $2,105,993$ & \\
\hline Worst & 449,154 & & $1,024,787$ & & $2,163,288$ & \\
\hline \# Best & 1 & & 1 & & 1 & \\
\hline$\# \leq \mathrm{BB}$ & 0 & & 0 & & 10 & \\
\hline \multicolumn{7}{|c|}{ GA" } \\
\hline Best & 415,316 & \multirow{5}{*}{$\begin{array}{c}508 \\
(\text { avg) }\end{array}$} & 894,697 & \multirow{5}{*}{$\begin{array}{l}1,688 \\
\text { (avg) }\end{array}$} & $2,036,104$ & \multirow{5}{*}{$\begin{array}{l}6,673 \\
\text { (avg) }\end{array}$} \\
\hline Average & 424,754 & & 927,095 & & $2,132,776$ & \\
\hline Worst & 438,026 & & 956,811 & & $2,360,098$ & \\
\hline \# Best & 1 & & 1 & & 1 & \\
\hline$\# \leq \mathbf{B B}$ & 1 & & 0 & & 10 & \\
\hline \multicolumn{7}{|c|}{ GA"' } \\
\hline Best & 413,602 & \multirow{5}{*}{$\begin{array}{c}503 \\
\text { (avg) }\end{array}$} & 896,769 & \multirow{5}{*}{$\begin{array}{l}1,576 \\
\text { (avg) }\end{array}$} & $1,881,208$ & \multirow{5}{*}{$\begin{array}{l}4,434 \\
\text { (avg) }\end{array}$} \\
\hline Average & 424,257 & & 919,832 & & $1,934,792$ & \\
\hline Worst & 439,527 & & 942,418 & & $2,008,270$ & \\
\hline \# Best & 1 & & 1 & & 1 & \\
\hline$\# \leq \mathbf{B B}$ & 1 & & 0 & & 10 & \\
\hline
\end{tabular}




\subsection{Experiment 3}

Experiment 3 considers the hottest 24-hour period to occur in the month of July. This period is of interest to analyze because the steam demand on the plant is the lowest during the year. The plant is run completely on gas. When setting up the experiments the boiler efficiency equations for gas are used. The average ambient temperature over the 24-hour period is around $29^{\circ} \mathrm{C}$ which results in the nominal rating of the gas turbine, duct burner and HRSG to be in the range of $9,000 \mathrm{~kW}, 18,900 \mathrm{~kW}$ and $38,000 \mathrm{~kW}$, respectively. Table A1 in the appendix shows the hourly recorded ambient temperature and total electric and steam demands.

The summary of the experiment results are given in Table 5. For all three planning horizon sizes $\mathrm{BB}(\mathrm{T})$ produces integer infeasible solutions. Hence $\mathrm{BB}(1)$ problems are solved. The total CPU time to solve 24 hourly Problem $\mathrm{P}(\mathrm{t})$ by $\mathrm{BB}$ is less than 2 seconds. GA proves to be more consistent in finding integer feasible solutions. For Problem P(t,6) GA' finds the most optimum solution once, GA" once and GA", twice. For Problem P(t,12) GA" and GA" find the most optimum solution once. For Problem P(t,24) GA" "finds the most optimum solution once. For Problem P(t,6) the average CPU time for GA' is 814 seconds, for GA" is 412 seconds and GA" "' is 433 seconds. For Problem $\mathrm{P}(\mathrm{t}, 12)$ the average CPU time for GA' is 2,393 seconds, for GA" is 2,186 seconds and GA" ' is 1,979 seconds. For Problem $\mathrm{P}(\mathrm{t}, 24)$ the average CPU time for GA' is 6,687 seconds, for GA" is 6,148 seconds and GA"' is 6,763 seconds.

The continuous variable values corresponding to PR, BB(1) and the best GA", are given in Table A2 in the appendix. In PR steam was produced by the HRSG and one additional boiler. But the duct burner of the HRSG was switched off after 5 hours of operation and the boiler continued operation. GA identifies that it is better to switch off the boiler and continue operation of the duct burner to increase output from the HRSG. This result is an outcome of the differences in thermodynamic characteristics of the energy conversion equipment when all are using gas as the fuel. It can be verified by examining the gas turbine and HRSG characteristics in Fig. 2 and Table 1 and the boiler characteristics in Fig. 3. When the gas turbine and HRSG are at higher loads, they jointly have better energy conversion efficiencies than any of the boilers. Table 8 summarizes the plant performance for the three schedules. In PR plant energy efficiency was 79.99\% and 1 start/stop occurred. BB reduces the efficiency to $62.50 \%$ and has 65 start/stops. GA increases the efficiency by $9 \%$ to $89.32 \%$ and has 1 start/stop.

Table 5 Experiment 3 Results Summary

\begin{tabular}{|c|c|c|c|c|c|c|}
\hline & \multicolumn{2}{|c|}{$\mathbf{P}(\mathbf{t}, \mathbf{6})$} & \multicolumn{2}{|c|}{$\mathbf{P}(\mathbf{t}, \mathbf{1 2})$} & \multicolumn{2}{|c|}{$\mathbf{P}(\mathbf{t}, \mathbf{2 4})$} \\
\hline & $\begin{array}{l}\text { Obj. Func. } \\
\text { (kWh) }\end{array}$ & $\begin{array}{c}\text { CPU Time } \\
\text { (s) }\end{array}$ & $\begin{array}{c}\text { Obj. Func. } \\
\text { (kWh) }\end{array}$ & $\begin{array}{c}\text { CPU Time } \\
\text { (s) }\end{array}$ & $\begin{array}{c}\text { Obj. Func. } \\
\text { (kWh) }\end{array}$ & $\begin{array}{c}\text { CPU Time } \\
\text { (s) }\end{array}$ \\
\hline LB & 244,884 & - & 474,559 & - & 969,465 & - \\
\hline $\mathbf{B B}(\mathbf{T})$ & $\mathrm{x}$ & 23 & $\mathrm{x}$ & 50 & $\mathrm{x}$ & 113 \\
\hline $\mathbf{B B}(1)$ & 721,516 & 0.33 & $1,326,626$ & 0.64 & $2,647,255$ & 1.67 \\
\hline \multicolumn{7}{|c|}{$\mathbf{G A}^{\prime}$} \\
\hline Best & 257,814 & \multirow{5}{*}{$\begin{array}{c}814 \\
\text { (avg) }\end{array}$} & 570,801 & \multirow{5}{*}{$\begin{array}{l}2,393 \\
\text { (avg) }\end{array}$} & $1,314,933$ & \multirow{5}{*}{$\begin{array}{l}6,687 \\
\text { (avg) }\end{array}$} \\
\hline Average & 272,171 & & 617,614 & & $1,405,420$ & \\
\hline Worst & 293,448 & & 716,555 & & $1,495,818$ & \\
\hline \# Best & 1 & & 1 & & 1 & \\
\hline$\# \leq \mathrm{BB}$ & 10 & & 10 & & 10 & \\
\hline \multicolumn{7}{|c|}{ GA" } \\
\hline Best & 257,814 & \multirow{5}{*}{$\begin{array}{c}412 \\
\text { (avg) }\end{array}$} & 505,053 & \multirow{5}{*}{$\begin{array}{l}2,186 \\
\text { (avg) }\end{array}$} & $1,325,673$ & \multirow{5}{*}{$\begin{array}{l}6,148 \\
\text { (avg) }\end{array}$} \\
\hline Average & 288,722 & & 524,970 & & $1,482,592$ & \\
\hline Worst & 318,632 & & 549,803 & & $1,791,059$ & \\
\hline \# Best & 1 & & 1 & & 1 & \\
\hline$\# \leq \mathrm{BB}$ & 10 & & 10 & & 10 & \\
\hline \multicolumn{7}{|c|}{ GA"' } \\
\hline Best & 257,814 & \multirow{5}{*}{$\begin{array}{c}433 \\
\text { (avg) }\end{array}$} & 505,053 & \multirow{5}{*}{$\begin{array}{l}1,979 \\
\text { (avg) }\end{array}$} & $1,040,469$ & \multirow{5}{*}{$\begin{array}{l}6,763 \\
\text { (avg) }\end{array}$} \\
\hline Average & 277,562 & & 524,576 & & $1,062,968$ & \\
\hline Worst & 296,264 & & 587,406 & & $1,098,332$ & \\
\hline \# Best & 2 & & 1 & & 1 & \\
\hline$\# \leq \mathbf{B B}$ & 10 & & 10 & & 10 & \\
\hline
\end{tabular}

\subsection{Experiment 4}

Experiment 4 considers a 24-hour period occurring in the month of October which is during the Fall season. This period is of interest to analyze because the steam demand begins to rise as summer recedes and winter approaches. Two boilers $(\mathrm{B} 1, \mathrm{~B} 2)$ are run on gas whereas the third boiler (B3) if needed is run on oil. When setting up the experiments, the appropriate efficiency equation for each boiler is used. The average ambient temperature over the 24-hour period is around $11^{\circ} \mathrm{C}$ which results in the nominal rating of the gas turbine, duct burner and HRSG to be in the range of $10,250 \mathrm{~kW}, 21,400 \mathrm{~kW}$ and $41,200 \mathrm{~kW}$, respectively. Table A1 in the appendix shows the hourly recorded ambient temperature and total electric and steam demands. 
The summary of the experiment results are given in Table 6. For Problem $\mathrm{P}(\mathrm{t}, 6), \mathrm{BB}(\mathrm{T})$ produces an integer feasible solution in less than 2 seconds and $\mathrm{BB}(1)$ solution is not needed. GA" finds the same solution as $\mathrm{BB}(\mathrm{T})$ once and GA" 'finds it twice. For Problem $\mathrm{P}(\mathrm{t}, 12)$, $\mathrm{BB}(\mathrm{T})$ produces an integer feasible solution in less than 15 seconds and $\mathrm{BB}(1)$ solution is not needed. None of the GA trials find better solutions than that of $\mathrm{BB}(\mathrm{T})$. For Problem $\mathrm{P}(\mathrm{t}, 24), \mathrm{BB}(\mathrm{T})$ takes about 23 minutes but reports an integer infeasible solution. Hence, $\mathrm{BB}(1)$ problems are solved and it takes less than 4 seconds to obtain the solution to 24 hourly Problem $\mathrm{P}(\mathrm{t})$ by $\mathrm{BB}$. GA finds several unique solutions to Problem $\mathrm{P}(\mathrm{t}, 24)$ of which the best one found by GA"' is the most optimum. For Problem P(t,6) the average CPU time for GA' is 730 seconds, for GA" is 483 seconds and GA" " is 435 seconds. For Problem P(t,12) the average CPU time for GA' is 2,872 seconds, for GA" is 1,533 seconds and GA"' is 1,886 seconds. For Problem $\mathrm{P}(\mathrm{t}, 24)$ the average CPU time for GA' is 6,032 seconds, for GA" is 6,848 seconds and GA" ${ }^{\prime \prime}$ is 5,156 seconds.

The continuous variable values corresponding to PR, $\mathrm{BB}(1)$ and the best GA", are given in Table A2 in the appendix.. In PR steam was produced by the HRSG and mostly one additional boiler running on gas and 1 start/stop occurred in the second boiler. GA identifies that it is better to increase the output from the HRSG and reduce the usage of the boilers. Table 8 summarizes the plant performance for the three schedules. PR resulted in the present plant energy efficiency to be $78.95 \%$. BB reduces the efficiency to $66.13 \%$ and has 50 start/stops. GA has 2 start/stops but increases the efficiency by $11 \%$ to $90.23 \%$.

Table 6 Experiment 4 Results Summary

\begin{tabular}{|c|c|c|c|c|c|c|}
\hline & \multicolumn{2}{|c|}{$\mathbf{P}(\mathbf{t}, \mathbf{6})$} & \multicolumn{2}{|c|}{$\mathbf{P}(\mathbf{t}, \mathbf{1 2})$} & \multicolumn{2}{|c|}{$\mathbf{P}(\mathbf{t}, \mathbf{2 4})$} \\
\hline & $\begin{array}{c}\text { Obj. Func. } \\
\text { (kWh) }\end{array}$ & $\begin{array}{c}\text { CPU Time } \\
\text { (s) }\end{array}$ & $\begin{array}{c}\text { Obj. Func. } \\
\text { (kWh) }\end{array}$ & $\begin{array}{c}\text { CPU Time } \\
\text { (s) }\end{array}$ & $\begin{array}{c}\text { Obj. Func. } \\
\text { (kWh) }\end{array}$ & $\begin{array}{c}\text { CPU Time } \\
\text { (s) }\end{array}$ \\
\hline LB & 315,649 & - & 626,002 & - & $1,257,455$ & - \\
\hline BB(T) & 331,077 & 1.81 & 648,781 & 15 & $\mathrm{x}$ & 1,402 \\
\hline $\mathbf{B B}(1)$ & - & - & - & - & $2,466,603$ & 3.65 \\
\hline \multicolumn{7}{|c|}{ GA' $^{\prime}$} \\
\hline Best & 331,236 & \multirow{5}{*}{$\begin{array}{c}730 \\
\text { (avg) }\end{array}$} & 718,468 & \multirow{5}{*}{$\begin{array}{l}2,872 \\
\text { (avg) }\end{array}$} & $1,585,219$ & \multirow{5}{*}{$\begin{array}{l}6,032 \\
\text { (avg) }\end{array}$} \\
\hline Average & 348,837 & & 767,848 & & $1,755,013$ & \\
\hline Worst & 384,993 & & 838,918 & & $1,934,697$ & \\
\hline \# Best & 1 & & 1 & & 1 & \\
\hline$\# \leq \mathbf{B B}$ & 0 & & 0 & & 10 & \\
\hline \multicolumn{7}{|c|}{ GA" } \\
\hline Best & 331,077 & \multirow{5}{*}{$\begin{array}{c}483 \\
\text { (avg) }\end{array}$} & 649,354 & \multirow{5}{*}{$\begin{array}{l}1,533 \\
\text { (avg) }\end{array}$} & $1,578,770$ & \multirow{5}{*}{$\begin{array}{l}6,848 \\
\text { (avg) }\end{array}$} \\
\hline Average & 340,935 & & 721,631 & & $1,717,038$ & \\
\hline Worst & 362,784 & & 784,634 & & $1,868,481$ & \\
\hline \# Best & 1 & & 1 & & 1 & \\
\hline$\# \leq \mathbf{B B}$ & 1 & & 0 & & 10 & \\
\hline \multicolumn{7}{|c|}{ GA"' } \\
\hline Best & 331,077 & \multirow{5}{*}{$\begin{array}{c}435 \\
\text { (avg) }\end{array}$} & 648,939 & \multirow{5}{*}{$\begin{array}{l}1,886 \\
\text { (avg) }\end{array}$} & $1,325,302$ & \multirow{5}{*}{$\begin{array}{l}5,156 \\
\text { (avg) }\end{array}$} \\
\hline Average & 354,502 & & 680,818 & & $1,422,951$ & \\
\hline Worst & 379,756 & & 773,391 & & $1,520,401$ & \\
\hline \# Best & 2 & & 1 & & 1 & \\
\hline$\# \leq \mathbf{B B}$ & 1 & & 0 & & 10 & \\
\hline
\end{tabular}

\subsection{Summary}

The numerical experiments show the proposed genetic algorithm method finds more optimal solutions than branch-and-bound. In many cases branch-and-bound does not find integer feasible solutions and is also seen to have an exponential increase in CPU time for a linear increase in planning horizon size. Among the genetic procedures experimented with, GA", (ranked scaling, stochastic uniform selection, scattered crossover, Gaussian mutation) finds the most optimum solutions and has the lowest average CPU time.

Since the objective function values of the three planning horizon sizes differ in order of magnitude, the optimality gap is a more appropriate metric to compare the performance of the genetic algorithm across all experiments. Table 7 summarizes the experiment results in terms of the optimality gap and average CPU time. The optimality gap is a relative metric defined as the difference between the objective function value and the lower bound and is normalized with the objective function value. The gaps for the best, average and worst objective function values along with the average CPU time for each set of trials are calculated. The gaps for branch-and-bound solutions are also calculated for comparison. The genetic algorithm is able to achieve low optimality gaps in reasonable CPU time. In one case the best gap achieved is negative because the objective function value is lower than the lower bound which happens because of the nonconvexity of the problem. The algorithm achieves low gaps regardless of the problem size. 
Table 7 Algorithm Benchmarks

\begin{tabular}{|c|c|c|c|c|c|c|c|}
\hline & & \multicolumn{2}{|c|}{$\mathbf{P}(\mathbf{t}, \mathbf{6})$} & \multicolumn{2}{|c|}{$\mathbf{P}(\mathbf{t}, 12)$} & \multicolumn{2}{|c|}{$\mathbf{P}(\mathbf{t}, 24)$} \\
\hline & & $\begin{array}{c}\text { Opt. Gap } \\
(\%)\end{array}$ & $\begin{array}{c}\text { Avg. CPU } \\
\text { Time (s) }\end{array}$ & $\begin{array}{c}\text { Opt. Gap } \\
(\%)\end{array}$ & $\begin{array}{c}\text { Avg. CPU } \\
\text { Time (s) }\end{array}$ & $\begin{array}{c}\text { Opt. Gap } \\
(\%)\end{array}$ & $\begin{array}{c}\text { Avg. CPU } \\
\text { Time (s) }\end{array}$ \\
\hline \multicolumn{8}{|c|}{ Experiment 1} \\
\hline \multicolumn{2}{|c|}{$\mathbf{B B}(\mathbf{T}) / \mathbf{B B}(1)$} & 0.93 & - & 1.03 & - & 9.09 & - \\
\hline \multirow{3}{*}{$\mathbf{G A}^{\prime}$} & Best & 0.93 & \multirow{3}{*}{658} & 3.99 & \multirow{3}{*}{2,277} & 7.35 & \multirow{3}{*}{6,428} \\
\hline & Average & 3.28 & & 6.39 & & 10.55 & \\
\hline & Worst & 5.25 & & 11.59 & & 19.27 & \\
\hline \multirow{3}{*}{ GA" } & Best & 1.46 & \multirow{3}{*}{511} & 3.18 & \multirow{3}{*}{2,314} & 7.40 & \multirow{3}{*}{6,681} \\
\hline & Average & 2.82 & & 4.70 & & 10.25 & \\
\hline & Worst & 4.22 & & 7.06 & & 14.27 & \\
\hline \multirow{3}{*}{ GA"' } & Best & 0.22 & \multirow{3}{*}{528} & 0.55 & \multirow{3}{*}{2,055} & 1.27 & \multirow{3}{*}{6,112} \\
\hline & Average & 1.72 & & 2.15 & & 2.45 & \\
\hline & Worst & 3.62 & & 5.98 & & 5.35 & \\
\hline \multicolumn{8}{|c|}{ Experiment 2} \\
\hline \multicolumn{2}{|c|}{$\mathbf{B B}(\mathbf{T}) / \mathbf{B B}(\mathbf{1})$} & 0.70 & - & 1.22 & - & 37.19 & - \\
\hline \multirow{3}{*}{$\mathbf{G A}^{\prime}$} & Best & 0.70 & \multirow{3}{*}{602} & 7.88 & \multirow{3}{*}{2,060} & 10.72 & \\
\hline & Average & 4.64 & & 10.91 & & 13.89 & 7,010 \\
\hline & Worst & 7.81 & & 13.77 & & 16.18 & \\
\hline & Best & 0.30 & & 1.23 & & 10.94 & \\
\hline GA" & Average & 2.51 & 508 & 4.68 & 1,688 & 14.98 & 6,673 \\
\hline & Worst & 5.47 & & 7.64 & & 23.17 & \\
\hline & Best & -0.11 & & 1.46 & & 3.61 & \\
\hline GA"'" & Average & 2.40 & 503 & 3.93 & 1,576 & 6.28 & 4,434 \\
\hline & Worst & 5.79 & & 6.23 & & 9.70 & \\
\hline & & & Exper & hent 3 & & & \\
\hline BB & B $(1)$ & 66.06 & - & 64.23 & - & 63.38 & - \\
\hline & Best & 5.02 & & 16.86 & & 26.27 & \\
\hline $\mathbf{G A}^{\prime}$ & Average & 10.03 & 814 & 23.16 & 2,393 & 31.02 & 6,687 \\
\hline & Worst & 16.55 & & 33.77 & & 35.19 & \\
\hline & Best & 5.02 & & 6.04 & & 26.87 & \\
\hline GA" & Average & 15.18 & 412 & 9.60 & 2,186 & 34.61 & 6,148 \\
\hline & Worst & 23.15 & & 13.69 & & 45.87 & \\
\hline & Best & 5.02 & & 6.04 & & 6.82 & \\
\hline GA"'" & Average & 11.77 & 433 & 9.53 & 1,979 & 8.80 & 6,763 \\
\hline & Worst & 17.34 & & 19.21 & & 11.73 & \\
\hline & & & Exper & eent 4 & & & \\
\hline BB & BB(1) & 4.66 & - & 3.51 & - & 49.02 & - \\
\hline & Best & 4.71 & & 12.87 & & 20.68 & \\
\hline $\mathbf{G A}^{\prime}$ & Average & 9.51 & 730 & 18.47 & 2,872 & 28.35 & 6,032 \\
\hline & Worst & 18.01 & & 25.38 & & 35.01 & \\
\hline & Best & 4.66 & & 3.60 & & 20.35 & \\
\hline GA" & Average & 7.42 & 483 & 13.25 & 1,533 & 26.77 & 6,848 \\
\hline & Worst & 12.99 & & 20.22 & & 32.70 & \\
\hline & Best & 4.66 & & 3.53 & & 5.12 & \\
\hline GA"' & Average & 10.96 & 435 & 8.05 & 1,886 & 11.63 & 5,156 \\
\hline & Worst & 16.88 & & 19.06 & & 17.29 & \\
\hline
\end{tabular}

To make a final comparison across the three problem sizes, the best gaps of GA" " from the four experiments are averaged. The average best gaps are 2.44, 2.89 and $4.20 \%$ for the three problem sizes. Similarly, the average CPU time of GA" from the four experiments are also averaged. These are calculated to be 475, 1,874 and 5,616 seconds. Fig. 7 plots these averaged best gaps and twice averaged CPU times for GA"'. The figure indicates that on average the best optimality gap achieved by the proposed genetic algorithm method does not depend to a great extent on the problem size whereas the CPU time increases linearly with the problem size.

Altogether, 360 trials were performed for the genetic algorithm. The trials involved variations in number of problem variables and constraints, variations in coefficients of objective function terms, variations in constraint vector values and variations in genetic procedures of scaling, selection, crossover and mutation. The numerous trials and wide variations in experimental conditions are statistically significant to draw inferences about the consistency and robustness of the proposed genetic algorithm. It can be inferred that the proposed genetic algorithm has strong search capabilities for mixed 0-1 nonlinear programming problems. It evaluates several more integer feasible solutions in the search 
process as compared to branch-and-bound which in many cases did not come across a single integer feasible solution. For large-scale nonconvex problems where global optimality is unknown and near optimal solutions are sufficient to make operational planning decisions, the proposed genetic algorithm method proves to be more versatile than branch-and-bound.

Table 8 gives the plant thermal performance for the 24-hour planning horizons. The proposed scheduling strategy increased plant energy efficiency by 5,10,9 and $11 \%$ in the four experimental studies. Although the genetic algorithm can cause random start/stops of equipment, it should be noted that operational planning strategies in medium to large-scale CHP plants are most likely to involve a human-inthe-loop strategy rather than a closed loop feedback system. The decision maker/plant operator can use the genetic algorithm solution to aid in the decision making process rather than implementing it as is.

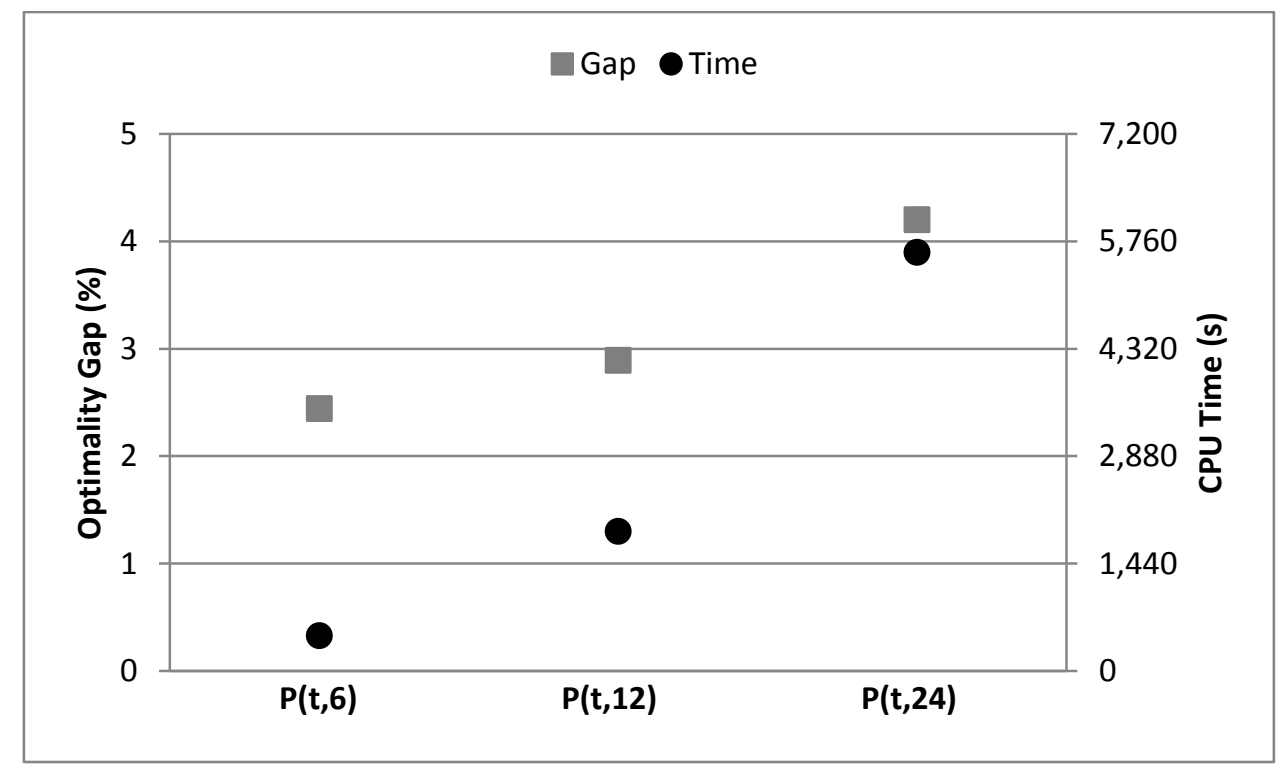

Fig. 7. Genetic Algorithm Performance

Table 8 Plant Thermal Performance

\begin{tabular}{|c|c|c|c|c|}
\hline & $\begin{array}{c}\text { Fuel Input } \\
\text { (kWh) }\end{array}$ & $\begin{array}{c}\text { Energy Output } \\
\text { (kWh) }\end{array}$ & \# Start/Stop & Efficiency (\%) \\
\hline \multicolumn{5}{|c|}{ Experiment 1 } \\
\hline PR & $2,669,958$ & $2,182,678$ & 3 & 81.75 \\
\hline BB & $2,729,126$ & $2,186,039$ & 22 & 80.10 \\
\hline GA & $2,512,828$ & $2,182,858$ & 4 & 86.87 \\
\hline \multicolumn{5}{|c|}{ Experiment 2 } \\
\hline PR & $2,111,167$ & $1,663,116$ & 1 & 78.78 \\
\hline BB & $2,887,093$ & $1,973,349$ & 47 & 68.35 \\
\hline GA & $1,881,208$ & $1,663,116$ & 4 & 88.41 \\
\hline \multicolumn{5}{|c|}{ Experiment 3 } \\
\hline PR & $1,133,596$ & 906,721 & 1 & 79.99 \\
\hline BB & $2,647,255$ & $1,654,448$ & 65 & 62.50 \\
\hline GA & $1,040,469$ & 929,341 & 1 & 89.32 \\
\hline \multicolumn{7}{|c|}{ Experiment 4 } \\
\hline PR & $1,512,457$ & $1,194,071$ & 1 & 78.95 \\
\hline BB & $2,466,603$ & $1,631,129$ & 50 & 66.13 \\
\hline GA & $1,325,302$ & $1,195,781$ & 2 & 90.23 \\
\hline
\end{tabular}




\section{Conclusion}

This paper presented a mixed 0-1 nonlinear programming formulation for operational planning in CHP plants. The formulation took into account nonlinear variations in equipment performance characteristics with changes in ambient temperature and operating load. The resulting problem was nonconvex and global optimality conditions were unknown. A genetic algorithm method was proposed and numerical experiments showed it was more reliable than branch-and-bound in finding integer feasible solutions and found more optimal solutions within reasonable CPU time. For the plant under consideration, the proposed scheduling strategy increased energy efficiency by $5-11 \%$.

Most operational planning strategies for CHP plants tend to use the MILP modeling paradigm. But the fundamental thermodynamic characteristics of energy conversion equipment are nonlinear. This makes the planning problems inherently MINLP problems. In order for planning models to agree with physical and thermodynamic realities, the nonlinear features of the model need to be kept intact during the computational solution phase. This paper showed that it is not necessary to apply linearization techniques to planning models in order to obtain practical solutions within reasonable time.

The planning model presented here was seeking to minimize total plant energy usage based on equipment efficiency characteristics rather than minimizing total cost based on purchase prices of fuels and selling prices of heat and power. This was done since if the problem is modeled as a cost optimization problem, then the relative differences in the cost coefficients of the objective function will influence the optimum solutions and the significance of using nonlinear efficiency characteristics in the model will get overshadowed.

Formulations of operational planning problems in plants like the one in this paper have their grounding in the first law of thermodynamics. They involve energy or cost objective functions and energy balance, energy demand and equipment load range constraints. The model in this paper involved a nonlinear objective function and nonlinear inequality, nonlinear equality and linear inequality constraints, thereby making it a general purpose approach. Hence, the methodology can easily be applied in plants with equal or lesser complicated energy flow networks.

\section{Acknowledgments}

This research was funded by the US Dept. of Energy under grant numbers DE-EE0005528 and DE-EE0006279.

\section{References}

[1] Sakawa M, Kato K, Ushiro S. Operational planning of district heating and cooling plants through genetic algorithms for mixed 0-1 linear programming. European Journal of Operational Research 2002;137(3):677-687.

[2] Sakawa M, Kato K, Ushiro S, Inaoka M. Operational planning of district heating and cooling plants using genetic algorithms for mixed integer programming. Applied Soft Computing 2001;1(2):139-150.

[3] Sakawa M, Kato K, Ushiro S. Operation planning of district heating and cooling plants through genetic algorithms for nonlinear 0-1 programming. Computers and Mathematics with Applications 2001;42(10-11):1365-1378.

[4] Saravanan B, Das S, Sikri S, Kothari D. A solution to the unit commitment problem-a review. Frontiers in Energy 2013;7(2):223-236.

[5] Xia X, Elaiw A. Optimal dynamic economic dispatch of generation: A review. Electric Power Systems Research 2010;80(8):975-986.

[6] Trespalacios F, Grossmann I. Review of mixed-integer nonlinear and generalized disjunctive programming methods. Chemie Ingenieur Technik 2014;86(7):991-1012.

[7] Floudas C, Gounaris C. A review of recent advances in global optimization. Journal of Global Optimization 2009;45(1):3-38.

[8] Cavalieri F, Roversi A, Ruggeri R. Use of mixed integer programming to investigate optimum running conditions for a thermal power station and possible extension to capacity. Operational Research Quarterly 1971;22(3):221-236.

[9] Logendran R, Oudheusden D. Optimal operation for a bi-fuel thermal power plant by mathematical programming. European Journal of Operational Research 1981;8(3):226-234.

[10] Chisman J. Optimal electric power load-dispatching. Computers and Operations Research 1979;6(1):53-58.

[11] Gardner D, Rogers J. Joint planning of combined heat and power and electric power systems: An efficient model formulation. European Journal of Operational Research 1997;102(1):58-72.

[12] Makkonen S, Lahdelma R. Non-convex power plant modeling in energy optimization. European Journal of Operational Research 2006;171(3):1113-1126.

[13] Rong A, Lahdelma R. An efficient envelope-based branch-and-bound algorithm for non-convex combined heat and power production planning. European Journal of Operational Research 2007;183(1):412-431.

[14] Rong A, Hakonen H, Lahdelma R. A dynamic regrouping based sequential dynamic programming algorithm for unit commitment of combined heat and power systems. Energy Conversion and Management 2009;50(4):1108-1115.

[15] Viswanathan J, Grossmann I. A combined penalty function and outer-approximation method for MINLP optimization. Computers and Chemical Engineering 1990;14(7):769-782.

[16] Quesada I, Grossmann I. An LP/NLP based branch-and-bound algorithm for convex MINLP optimization problems. Computers and Chemical Engineering 1992;16(10-11):937-947.

[17] Iyer R, Grossmann I. Optimal multiperiod operational planning for utility systems. Computers and Chemical Engineering 1997;21(8):787800.

[18] Mitra S, Sun L, Grossmann I. Optimal scheduling of industrial combined heat and power plants under time-sensitive electricity prices. Energy 2013;54:194-211. 
[19] Adjiman C, Androulakis I, Floudas C. Global optimization of mixed-integer nonlinear problems. American Institute of Chemical Engineers Journal 2000;46(9):1769-1797.

[20] Leyffer S. Integrating SQP and branch-and-bound for mixed integer nonlinear programming. Computational Optimization and Applications 2001;18(3):295-309.

[21] Pruitt K, Leyffer S, Newman A, Braun R. A mixed-integer nonlinear program for the optimal design and dispatch of distributed generation systems. Optimization and Engineering 2014;15(1):167-197.

[22] Pruitt K, Braun R, Newman A. Evaluating shortfalls in mixed-integer programming approaches for the optimal design and dispatch of distributed generation systems. Applied Energy 2013;102:386-398.

[23] Deep K, Singh K, Kansal M, Mohan C. A real coded genetic algorithm for solving integer and mixed integer optimization problems. Applied Mathematics and Computation 2009;212(2):505-518.

[24] Savola T, Tveit T, Fogelholm C. A MINLP model including the pressure levels and multiperiods for CHP process optimisation. Applied Thermal Engineering 2007;27(11-12):1857-1867.

[25] Tveit T, Savola T, Gebremedhin A, Fogelholm C. Multi-period MINLP model for optimising operation and structural changes to CHP plants in district heating networks with long-term thermal storage. Energy Conversion and Management 2009;50(3):639-647.

[26] Kjeldsen N, Chiarandini M. Heuristic solutions to the long-term unit commitment problem with cogeneration plants. Computers and Operations Research 2012;39(2):269-282.

[27] Bosman M, Bakker V, Molderink, Hurink J, Smit G. Planning the production of a fleet of domestic combined heat and power generators. European Journal of Operational Research 2012;216(1):140-151.

[28] Dotzauer E. Simple model for prediction of loads in district-heating systems. Applied Energy 2002;73(3-4):277-284.

[29] Pedersen L, Stang J, Ulseth R. Load prediction method for heat and electricity demand in buildings for the purpose of planning for mixed energy distribution systems. Energy and Buildings 2008;40(7):1124-1134.

[30] Holmstrom K, Goran A, Edvall M. User's Guide for TOMLAB/MINLP. TOMLAB Optimization.

[31] Mathworks Inc. Matlab Global Optimization Toolbox User's Guide. 


\section{Table A1 Problem Data}

\begin{tabular}{|c|c|c|c|c|c|c|c|c|c|c|c|c|c|c|c|c|c|c|c|c|c|c|c|c|}
\hline Hour & 1 & 2 & 3 & 4 & 5 & 6 & 7 & 8 & 9 & 10 & 11 & 12 & 13 & 14 & 15 & 16 & 17 & 18 & 19 & 20 & 21 & 22 & 23 & 24 \\
\hline \multicolumn{25}{|c|}{ Experiment 1 } \\
\hline $\mathbf{A}(\mathbf{K})$ & 264.25 & 264.35 & 264.46 & 265.02 & 263.99 & 263.32 & 262.80 & 262.24 & 261.78 & 261.28 & 260.72 & 260.50 & 260.20 & 259.97 & 259.41 & 259.22 & 258.54 & 258.37 & 258.22 & 258.23 & 258.51 & 259.56 & 261.30 & 263.54 \\
\hline $\mathrm{E}_{\text {dema }}(\mathbf{k W})$ & 8.893 & 8,850 & 8,996 & 9,007 & 9,097 & 9,261 & 8,400 & 8,311 & 8,250 & 8,161 & 8,103 & 7,946 & 7,926 & 7,899 & 8,599 & 8,599 & 8,675 & 8,742 & 9,198 & 9,966 & 9,995 & 10,031 & 9,044 & 10,227 \\
\hline$Q_{\text {SI Idend }}(\mathbf{k W})$ & 39,167 & 38,698 & 38,366 & 37,925 & 38,340 & 38,726 & 39,415 & 39,038 & 39,317 & 39,593 & 39,531 & 39,577 & 39,945 & 40,092 & 39,630 & 40,687 & 41,952 & 43,250 & 44,933 & 47,142 & 47,156 & 45,257 & 44,825 & 42,688 \\
\hline$Q_{\text {Ssdemd }}(\mathbf{k W})$ & 39,167 & 38,698 & 38,366 & 37,925 & 38,340 & 38,726 & 39,415 & 39,038 & 39,317 & 39,593 & 39,531 & 39,577 & 39,945 & 40,092 & 39,630 & 40,687 & 41,952 & 43,250 & 44,933 & 47,142 & 47,156 & 45,257 & 44,825 & 42,688 \\
\hline \multicolumn{25}{|c|}{ Experiment 2} \\
\hline $\mathbf{A}(\mathbf{K})$ & 276.39 & 277.97 & 279.00 & 280.07 & 277.11 & 274.77 & 273.18 & 272.07 & 271.26 & 270.57 & 269.78 & 269.31 & 269.15 & 268.77 & 268.82 & 268.84 & 269.05 & 269.23 & 269.54 & 269.52 & 270.34 & 272.40 & 274.31 & 275.67 \\
\hline $\mathrm{E}_{\text {tama }}(\mathrm{kW})$ & 10,178 & 10,131 & 10,106 & 10,023 & 10,124 & 10,176 & 13,574 & 14,651 & 14,881 & 14,962 & 14,738 & 14,016 & 13,517 & 13,189 & 12,843 & 12,546 & 12,552 & 12.858 & 13,451 & 14,250 & 14,796 & 14,614 & 14,432 & 14,290 \\
\hline 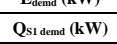 & 27,359 & 26,567 & 25,381 & 25,491 & 25,914 & 27,831 & 27,213 & 27,932 & 28,678 & 29,275 & 29,559 & 29,497 & 28,725 & 28,014 & 27,994 & 27,176 & 26,804 & 28,467 & 29,265 & 31,467 & 31,511 & 30,329 & 28,721 & 26,94 \\
\hline \multirow{2}{*}{\multicolumn{25}{|c|}{$\begin{array}{ll}22,3,45 \\
\text { Experiment } 3\end{array}$}} \\
\hline & & & & & & & & & & & & & & & & & & & & & & & & \\
\hline$A(\mathbf{K})$ & 306.71 & 308.46 & 308.81 & 309.15 & 308.57 & 308.29 & 307.17 & 305.56 & 303.75 & 301.19 & 299.23 & 298.21 & 297.08 & 296.23 & 295.29 & 294.77 & 294.15 & 295.26 & 297.23 & 299.20 & 301.01 & 302.60 & 304.66 & 305.98 \\
\hline $\mathrm{E}_{\text {aum }}(\mathbf{k W})$ & 10,449 & 10,089 & 9,949 & 10,372 & 10,292 & 10,214 & 10,161 & 10,287 & 10,268 & 10,478 & 10.507 & 10,590 & 10,614 & 10,636 & 10,462 & 10,813 & 10,581 & 11,087 & 11,265 & 11,287 & 11,278 & 11,267 & 11,073 & 11,046 \\
\hline$Q_{\text {SI demad }}(\mathbf{k} W)$ & 15,670 & 14,339 & 17,115 & 15,113 & 13,268 & 12,889 & 12,489 & 12,318 & 12,079 & 12,271 & 12,291 & 12,187 & 12,231 & 12,745 & 12,761 & 12,376 & 12,380 & 13,068 & 13,993 & 14,861 & 14,800 & 14,913 & 14,597 & 15,076 \\
\hline$Q_{\text {S2 dema }(\mathbf{k W})}$ & 15,670 & 14,339 & 17,115 & 15,113 & 13,268 & 12,889 & 12,489 & 12,318 & 12,079 & 12,271 & 12,291 & 12,187 & 12,231 & 12,745 & 12,761 & 12,376 & 12,380 & 13,068 & 13,993 & 14,861 & 14,800 & 14,913 & 14,597 & 15,076 \\
\hline \multicolumn{25}{|c|}{ Experiment 4} \\
\hline $\mathrm{A}(\mathrm{K})$ & 28.74 & 286.60 & 287.78 & 288.39 & 287.72 & 286.21 & 284.49 & 283.58 & 282.97 & 282.38 & 281.88 & 281.99 & 281.78 & 281.33 & 280.99 & 281.13 & 281.30 & 281.38 & 281.43 & 281.84 & $\begin{array}{ll}283.27 \\
\end{array}$ & 285.18 & 287.58 & 289.88 \\
\hline $\mathrm{E}_{\text {tama }}(\mathrm{kW})$ & 13,266 & 12,922 & 12,611 & 12,465 & 12,432 & 12,635 & 12,846 & 12,933 & 12,949 & 13,062 & 13,117 & 13,002 & 12,370 & 12,002 & 11,728 & 11,494 & 11,641 & 12,155 & 12,522 & 12,459 & 12,759 & 12,829 & 12,600 & 12,146 \\
\hline$Q_{\text {Sitam }}(\mathbf{k W})$ & 24,652 & 18,390 & 17,069 & 16,747 & 16,659 & 16,920 & 17,610 & 17,497 & 17,719 & 18,826 & 19,016 & 18,631 & 18,321 & $\begin{array}{ll}177,798 \\
\end{array}$ & 17,687 & 17,592 & 17,772 & 18.579 & 21,003 & 22,476 & $\begin{array}{ll}21,468 \\
\end{array}$ & 19,193 & 18. & 16,542 \\
\hline$Q_{S_{25 d \text { dend }}(\mathbf{k W})}$ & 24,652 & 18,390 & 17,069 & 16,747 & 16,659 & 16,920 & 17,610 & 17,497 & 17,719 & 18,826 & 19,016 & 18,631 & 18,321 & 17,798 & 17,687 & 17,592 & 17,772 & 18,579 & 21,003 & 22,476 & 21,468 & 19,193 & 18,395 & 16,542 \\
\hline
\end{tabular}

\section{Table A2 Continuous Variables}

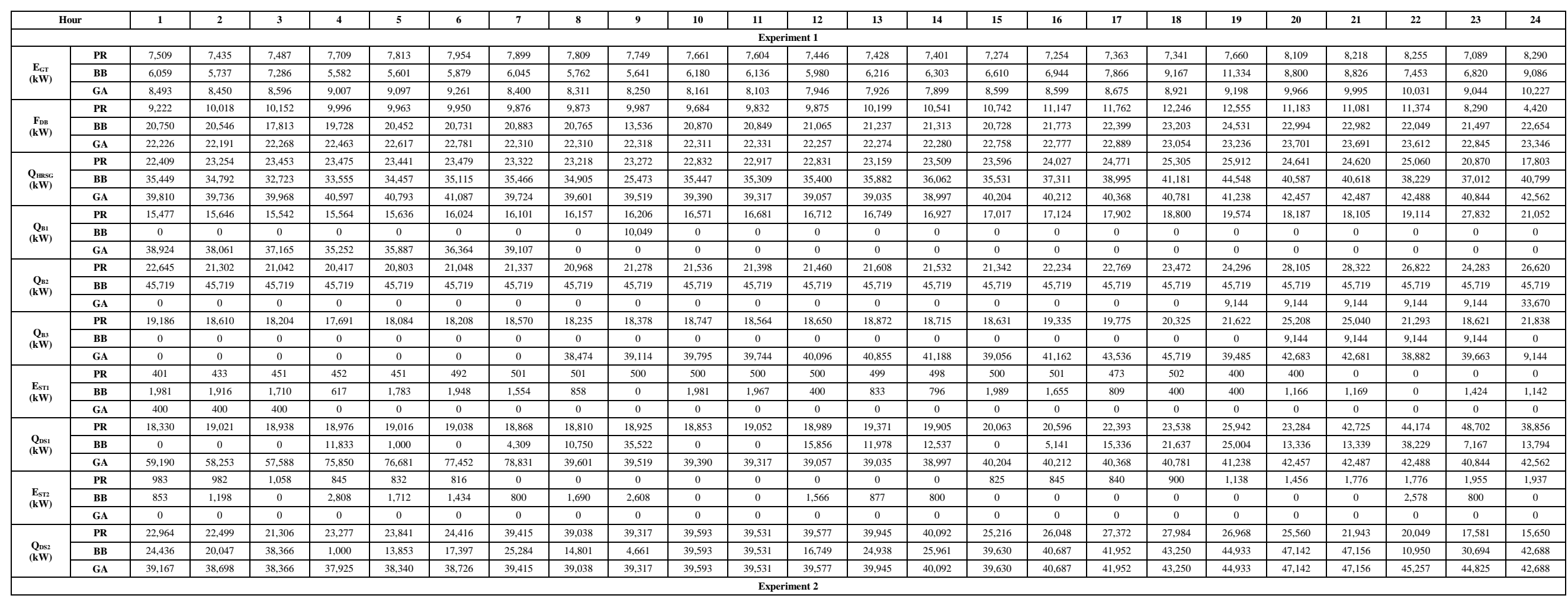




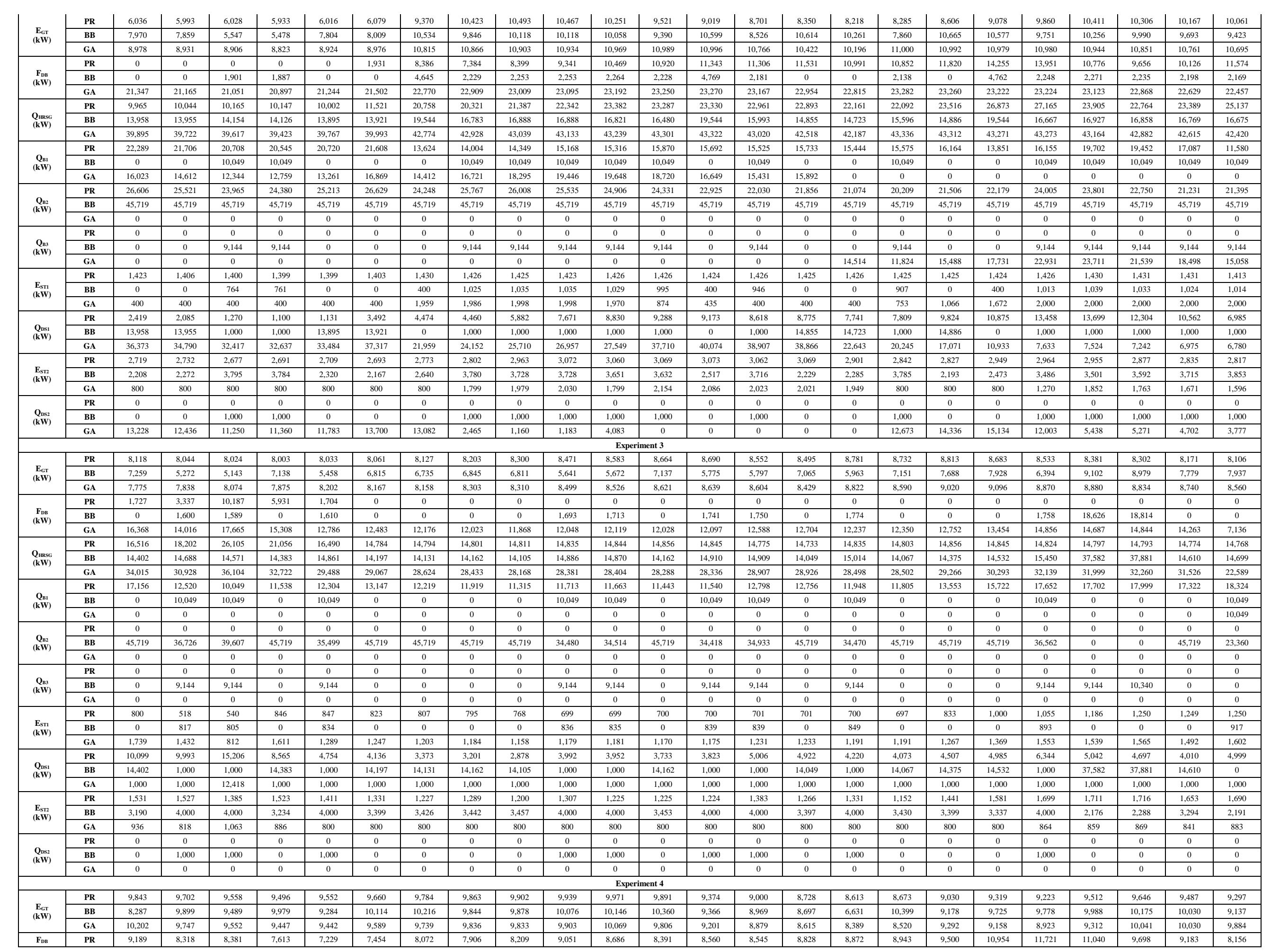




\begin{tabular}{|c|c|c|c|c|c|c|c|c|c|c|c|c|c|c|c|c|c|c|c|c|c|c|c|c|c|}
\hline$(\mathbf{k W})$ & BB & 2,012 & 0 & 0 & 20,793 & 0 & 21,086 & 21,314 & 0 & 0 & 0 & 0 & 21,643 & 0 & 0 & 0 & 1,947 & 0 & 0 & 0 & 0 & 0 & 0 & 20,902 & 0 \\
\hline & $\begin{array}{l}\text { GA } \\
\end{array}$ & 21,281 & 20,615 & 18,720 & $\begin{array}{l}18,246 \\
\end{array}$ & 18,131 & $\begin{array}{ll}18,554 \\
\end{array}$ & 19,587 & 19,429 & 19,780 & 21,328 & 21,477 & $\begin{array}{l}21,140 \\
\end{array}$ & $\begin{array}{l}20,927 \\
\end{array}$ & 20,325 & 20,292 & 20,247 & 20,441 & 21,055 & 18,456 & 20,713 & 19,030 & $\begin{array}{l}14,902 \\
\end{array}$ & $\begin{array}{l}3,570 \\
\end{array}$ & 11,440 \\
\hline \multirow{3}{*}{$\begin{array}{l}\text { HRss, } \\
\text { (kW) }\end{array}$} & PR & 23,071 & 22,150 & 22,228 & 21,377 & 20,934 & 21,127 & 21,749 & 21,537 & 21,847 & 22,768 & 22,332 & 21,959 & 21,780 & 21,447 & 21,516 & 21,486 & 21,631 & 22,547 & 24,451 & 25,332 & 24,875 & 23,570 & 23,081 & 21,981 \\
\hline & BB & 16,318 & 15,063 & 14,948 & 40,435 & 14,872 & 40,795 & 41,074 & 14,977 & 14,975 & $\begin{array}{r}15,029 \\
\end{array}$ & 15,041 & 41,469 & 14,757 & 14,585 & 14,458 & 15,155 & 15,112 & 14,672 & 14,882 & 14,912 & 15,020 & 15,124 & 40,570 & 14,866 \\
\hline & GA & 41,034 & 39,955 & 37,196 & 36,512 & 36,308 & 36,886 & 38,327 & 38,090 & 38,554 & 40,810 & 41,079 & 40,458 & 39,811 & 38,719 & 38,487 & 38,290 & 38,665 & 40,021 & 36,227 & 39,344 & 37,239 & 32,031 & 30,397 & 27,734 \\
\hline \multirow{3}{*}{$\begin{array}{c}\mathbf{Q}_{\mathrm{B1}} \\
(\mathbf{k W}\end{array}$} & PR & 20,513 & 17,851 & 14,962 & 15,086 & 15,264 & 15,688 & 16,533 & 16,527 & 16,638 & 18,006 & 18,845 & 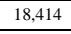 & $\begin{array}{l}17,859 \\
\end{array}$ & 17,152 & 16,858 & 16,581 & 16,881 & $\begin{array}{l}17,736 \\
\end{array}$ & 20,759 & 22,856 & 21,309 & 18,000 & 16,822 & 13,952 \\
\hline & BB & 10,049 & 0 & 0 & 0 & 0 & 0 & 0 & 0 & 0 & 0 & 0 & 0 & 0 & 0 & 0 & $\begin{array}{ll}10,049 \\
\end{array}$ & 21,674 & 0 & 0 & 0 & 0 & 25,917 & 0 & 10,049 \\
\hline & GA & 11,335 & 0 & 0 & 0 & 0 & 0 & 0 & 0 & 0 & 0 & 0 & 0 & 0 & 0 & 0 & 0 & 0 & 0 & 0 & 0 & 0 & 0 & 0 & 0 \\
\hline \multirow{3}{*}{$\begin{array}{c}\mathbf{Q}_{\mathrm{n} 2} \\
(\mathrm{kWW})\end{array}$} & PR & 9,144 & 0 & 0 & 0 & 0 & 0 & 0 & 0 & 0 & 0 & 0 & 0 & 0 & 0 & 0 & 0 & 0 & 0 & 0 & 0 & 0 & 0 & 0 & 0 \\
\hline & BB & 45,571 & 45,719 & 45,719 & 0 & 45,719 & 0 & 0 & 45,719 & $\begin{array}{r}45,719 \\
\end{array}$ & 45,719 & 45,719 & 0 & 45,719 & $\begin{array}{r}45,719 \\
\end{array}$ & 45,719 & 39,559 & 0 & 45,719 & 45,719 & $\begin{array}{r}45,719 \\
\end{array}$ & 45,719 & 0 & 0 & 23,243 \\
\hline & GA & 0 & 0 & 0 & 0 & 0 & 0 & 0 & 0 & 0 & 0 & 0 & 0 & 0 & 0 & 0 & 0 & 0 & 0 & 0 & 0 & 0 & 0 & 0 & 0 \\
\hline \multirow{3}{*}{$\begin{array}{c}\mathbf{Q}_{\mathrm{B} 3} \\
(\mathbf{k W})\end{array}$} & $\begin{array}{l}\text { PR } \\
\end{array}$ & 0 & 0 & 0 & 0 & 0 & 0 & 0 & 0 & 0 & 0 & 0 & 0 & 0 & 0 & 0 & 0 & 0 & 0 & 0 & 0 & 0 & 0 & 0 & 0 \\
\hline & BB & 9,144 & 0 & 0 & 12,068 & 0 & 12,312 & $\begin{array}{ll}4,059 \\
\end{array}$ & 0 & 0 & 0 & 0 & $\begin{array}{ll}14,844 \\
\end{array}$ & 0 & 0 & 0 & 9,144 & 0 & 0 & $\begin{array}{l}0 \\
\end{array}$ & $\begin{array}{l}0 \\
\end{array}$ & $\begin{array}{l}0 \\
\end{array}$ & 0 & $\begin{array}{ll}14,628 \\
\end{array}$ & 0 \\
\hline & GA & $\begin{array}{l}0 \\
\end{array}$ & 0 & 0 & $\begin{array}{l}0 \\
\end{array}$ & 0 & $\begin{array}{l}0 \\
\end{array}$ & 0 & 0 & 0 & 0 & 0 & 0 & 0 & 0 & 0 & 0 & 0 & 0 & $\begin{array}{l}, 144 \\
\end{array}$ & 9,144 & 9,144 & 9,144 & 9,144 & 9,144 \\
\hline \multirow{3}{*}{ 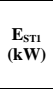 } & PR & 1,559 & 1,556 & 1,555 & 1,532 & 1,523 & 1,525 & 1,525 & 1,525 & 1,525 & 1,525 & 1,525 & 1,525 & 1,523 & 1,520 & 1,524 & 1,524 & 1,525 & 1,526 & 1,528 & 1,520 & 1,529 & 1,525 & 1,526 & 1,524 \\
\hline & BB & 979 & 0 & 0 & 0 & 0 & 0 & 0 & 0 & 0 & 0 & 0 & 0 & 0 & 0 & 0 & 863 & 442 & 0 & 0 & 0 & 0 & 1,496 & 0 & 934 \\
\hline & GA & 1,338 & 2,000 & 2,000 & 1,987 & 1,967 & 2,000 & 2,000 & 2,000 & 2,000 & 1,945 & 1,817 & 2,000 & 2,000 & 2,000 & 2,000 & 2,000 & 2,000 & $\begin{array}{l}1,670 \\
\end{array}$ & 1,959 & 2,000 & 2,000 & 1,542 & $\begin{array}{l}1,379 \\
\end{array}$ & 1,115 \\
\hline \multirow{3}{*}{$\begin{array}{c}\text { Qoss } \\
(\mathrm{kW})\end{array}$} & $\begin{array}{l}\text { PR } \\
\end{array}$ & 12,385 & 8,822 & 6,028 & $\begin{array}{l}5,528 \\
\end{array}$ & $\begin{array}{l}5,352 \\
\end{array}$ & $\begin{array}{l}5,955 \\
\end{array}$ & $\begin{array}{l}7,417 \\
\end{array}$ & 7,206 & $\begin{array}{l}7,626 \\
\end{array}$ & \begin{tabular}{|c|}
9,914 \\
\end{tabular} & 10,319 & 9,510 & 8,795 & 7,783 & 7,525 & 7,218 & 7,646 & 9,414 & 14,322 & 17,381 & 15,281 & 10,709 & $\begin{array}{l}, 028 \\
\end{array}$ & 5,086 \\
\hline & BB & 1,000 & 15,063 & 14,948 & 40,433 & 14,872 & 40,795 & 41,074 & 14,977 & 14,975 & 15,029 & 15,041 & 41,469 & 14,757 & 14,585 & 14,458 & 1,000 & 16,820 & 14,672 & 14,882 & 14,912 & 15,020 & 10,4 & 40,570 & 0 \\
\hline & GA & 23,391 & 4,315 & 1,556 & 1,000 & 1,000 & 1,246 & 2,687 & 2,450 & 2,914 & 5,720 & 7,277 & 4,818 & 4,171 & 3,079 & 2,847 & 2,650 & 3,025 & 7,696 & 1,000 & 3,704 & 1,599 & 1,000 & 1,000 & 1,000 \\
\hline \multirow{3}{*}{$\begin{array}{l}\begin{array}{l}\mathrm{E}_{512} \\
(\mathrm{~kW})\end{array}\end{array}$} & $\begin{array}{l}\text { PR } \\
\end{array}$ & 1,865 & 1,664 & 1,498 & 1,437 & 1,357 & 1,450 & 1,536 & 1,546 & 1,523 & 1,598 & 1,621 & 1,586 & 1,473 & 1,482 & 1,476 & 1,358 & 1,442 & $\begin{array}{l}1,599 \\
\end{array}$ & 1,676 & 1,716 & 1,718 & 1,658 & 1,587 & 1,325 \\
\hline & BB & 4,000 & \begin{tabular}{|l|l|}
3,024 \\
\end{tabular} & 3,121 & $\begin{array}{ll}2,486 \\
\end{array}$ & 3,148 & $\begin{array}{l}2,521 \\
\end{array}$ & $\begin{array}{ll}2,629 \\
\end{array}$ & $\begin{array}{r}3,089 \\
\end{array}$ & \begin{tabular}{ll|}
3,071 \\
\end{tabular} & 2,986 & 2,971 & 2,642 & 3,004 & $\begin{array}{l}3,033 \\
\end{array}$ & \begin{tabular}{|l|l|}
3,031 \\
\end{tabular} & 4,000 & 800 & 2,977 & 2,797 & 2,680 & 2,771 & $\begin{array}{ll}1,158 \\
\end{array}$ & 2,571 & 2,075 \\
\hline & GA & 1,727 & 1,175 & 1,059 & 1,030 & 1,023 & 1,046 & 1,107 & 1,097 & 1,116 & 1,214 & 1,230 & 1,196 & 1,169 & 1,123 & 1,113 & 1,105 & 1,121 & 1,192 & 1,405 & 1,535 & 1,446 & 1,246 & 1,192 & 1,147 \\
\hline \multirow{3}{*}{$\begin{array}{c}\mathrm{O}_{\mathrm{ss} 2} \\
\mathrm{kWW}\end{array}$} & PR & 1,566 & 5,548 & 4,980 & 4,613 & 3,789 & 4,585 & 4,879 & 5,096 & 4,613 & 4,361 & 4,434 & 4,425 & 3,454 & 4,073 & 4,117 & 2,873 & 3,648 & 4,623 & 3,073 & 2,053 & 3,080 & 4,677 & 4,665 & 3,551 \\
\hline & BB & 1,000 & 0 & 0 & 0 & $\begin{array}{l}0 \\
\end{array}$ & 0 & 0 & 0 & 0 & 0 & 0 & 0 & 0 & 0 & 0 & 1,000 & 3,641 & 0 & 0 & 0 & 0 & 1,000 & 0 & 0 \\
\hline & GA & 0 & 0 & 0 & 0 & 0 & 0 & 0 & 0 & 0 & 0 & 0 & 0 & 0 & 0 & 0 & 0 & 0 & 0 & 0 & 0 & 0 & 0 & 0 & 0 \\
\hline
\end{tabular}

